\title{
Thin Chalcogenide Films for Photonic Applications
}

\author{
Rossen Todorov, Jordanka Tasseva and Tsvetanka Babeva \\ Institute of Optical Materials and Technologies "Acad. J. Malinowski" \\ Bulgarian Academy of Sciences \\ Bulgaria
}

\section{Introduction}

In nature glass is formed as a result of rapid cooling and solidification of rock melts of volcanic origin. That hints at the existence of glass to have dated back since the dawn of creation. Man has quite soon borrowed the pattern to synthesize glass for their needs: in the production of glass beads and glazes for ceramic pots and vases (3500 BC), hollow glass items (1500 BC) - these developing further through the discovery of glassblowing (between $27 \mathrm{BC}$ and AD 14), leading to fabrication of cast glass windows by Romans (around AD 100) and glass sheets (11 th century) (http://glassonline.com/infoserv/history.html). Starting its applications as a non-transparent material for decoration purposes, glass has made a breakthrough to become used in a wide range of fields - from housing construction through optics (for lenses and protective coatings for mirrors), information processing (optical fibres and, in general, waveguides) and storage to photonics. The ingredients of the first accidentally man-synthesized glass were nitrate and sand, the latter being mostly composed of silica $\left(\mathrm{SiO}_{2}\right)$, usually in the form of quartz. On its part, quartz is the second most abundant mineral in the Earth's continental crust and is thus justifiable as a basic material in glassproduction. Its high glass-transition temperature, however, places some limitations for its applications and other substances, such as sodium carbonate, aluminium, boron, calcium, cerium, magnesium, lead, thorium oxides are added to facilitate the processing and modulate the optical properties, e.g. refractive index. Alternatively, there are non-silica containing glasses as: borate, fluoride, phosphate and chalcogenide. Namely "chalcogenides" stay in the scope of the present chapter to be revealed as superb materials for photonics and in particular - photonic crystals (PhC). It would be traced in Section 3 what are the properties that we strive to derive out from chalcogenides in order to conform to the theoretical considerations. In the following lines, however we will see what chalcogenides originally offer.

\section{Chalcogenide glasses and their properties}

The term "chalcogen" - meaning "ore former" (from "chalcos" old Greek for "ore") - is a characteristic name that was proposed by Fischer in 1932 to refer to the group of elements O, S, Se, and Te (Fischer, 2001). "Chalcogenides" is used to address chalcogen's compounds with elements such as As (arsenic), Ag (silver), Bi (bismuth), $\mathrm{Cu}$ (copper), Cd (cadmium), Fe 
(iron), Ga (gallium), Ge (germanium), In (indium), $\mathrm{Pb}$ (lead), $\mathrm{Na}$ (sodium), Sb (antimony), $\mathrm{Si}$ (silicon), Sn (tin), Tl (thallium), Zn (zinc), etc. As suggested by the above variety of elements entering in the formation of the chalcogenide glassy alloys, chalcogenides offer wide range of variation in their properties - e.g., in their index of refraction and optical band gap, as seen in the figure below. It is seen that the refractive index could be freely varied with the composition in $2-3.6$ range and the optical band-gap from 1.5 to nearly $2.8 \mathrm{eV}$.
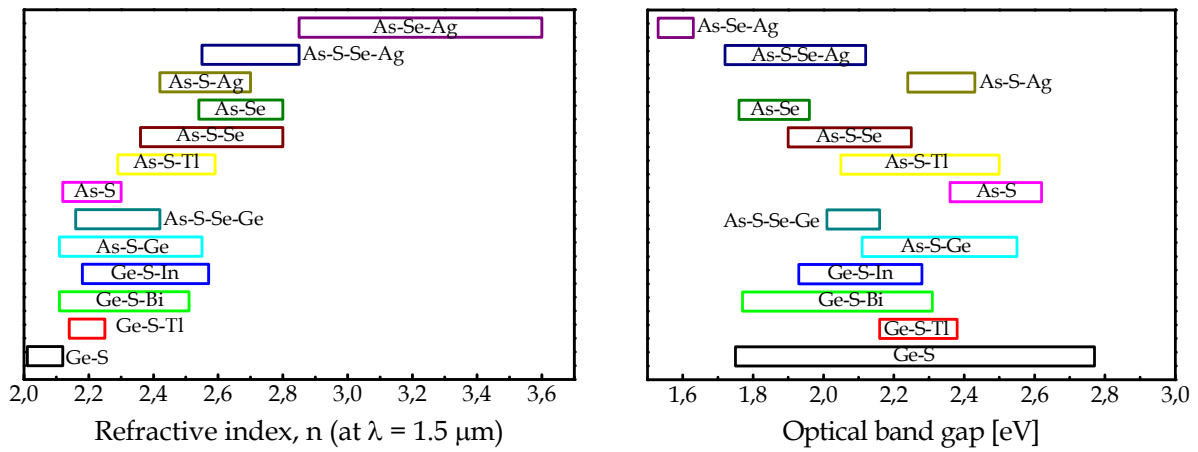

Fig. 1. Compositional variation of the refractive index and optical band-gap of chalcogenide glass thin films. The data depicted is taken from own studies and published elsewhere (Todorov et al., 2001, 2003; Tasseva et al., 2005, 2007, 2010; Kincl et al., 2009; Knotek et al., 2009; Petkov et al. , 2009).

Chalcogenide glasses, as implied by the latter term, are characterized by lack of a long-range order in the arrangement of the structural units within the glassy network, and are consequently in their nature - metastable. That fact is determining for the interesting effects resulting from the light-matter interactions in chalcogenides - electromagnetic radiation leads to modification of their structure and structural bonds. Chalcogens are two-fold coordinated with their atoms being in possession of lone-pair electrons, occupying states at the top of the valence band. Thus, exposure to light is associated with absorption of photons with certain energy, consumed for excitation of these anti-bonding electrons. That results to the formation of structural defects of one- or threefold coordinated chalcogen units (Kastner et al. 1976, Fritzsche, 1998, Liu et al., 2005). Considering all of the above and keeping in mind that the optical band gap for these materials is defined as the difference between the energies corresponding to the top of the valance and those, separating localized from delocalized states in the conductive band, we can interpret the above given values of the optical band gap as energies below which our materials are transparent. That provides transparency in the visible to IR region, where main telecommunication wavelengths are positioned, as well as the characteristic features of the so-called greenhouse gasses (water vapour, carbon dioxide, methane, nitrous oxide, and ozone) and biological molecules are located. That well-known fact can be utilized in fabrication of mid-IR guiding optical fibers for space and underground $\mathrm{CO}_{2}$ storage monitoring (Houizot et al., 2007, Charpentier et al., 2009), optical biosensors (Anne et al., 2009), etc.

To follow the thread started above for the interesting interactions between light and chalcogenides, we should say that these interactions when low- or high-intensity electromagnetic field involved are manifested respectively as a linear or nonlinear response 
of the chalcogenide media. Photoinduced darkening or bleaching, expressed by the shift of the absorption edge towards longer or shorter wavelengths, accompanied by increase or decrease of the refractive index and sometimes by contraction or expansion of the films are among the linear effects. The listed phenomena have been of a continuous interest for the scientific groups, dealing with chalcogenides (Barik et al., 2011; Skordeva et al., 2001) and will not be in the focus of the considerations in this section, but further. We will just report here some characteristic values for the photoinduced refractive index change of our materials since, as it will be shown in the next sections, a target parameter in the fabrication of $\mathrm{PhC}$ is the high optical contrast, that can be post-tuned by simply exposing the structure to light, accounting namely on the induced modifications in the photosensitive medium.
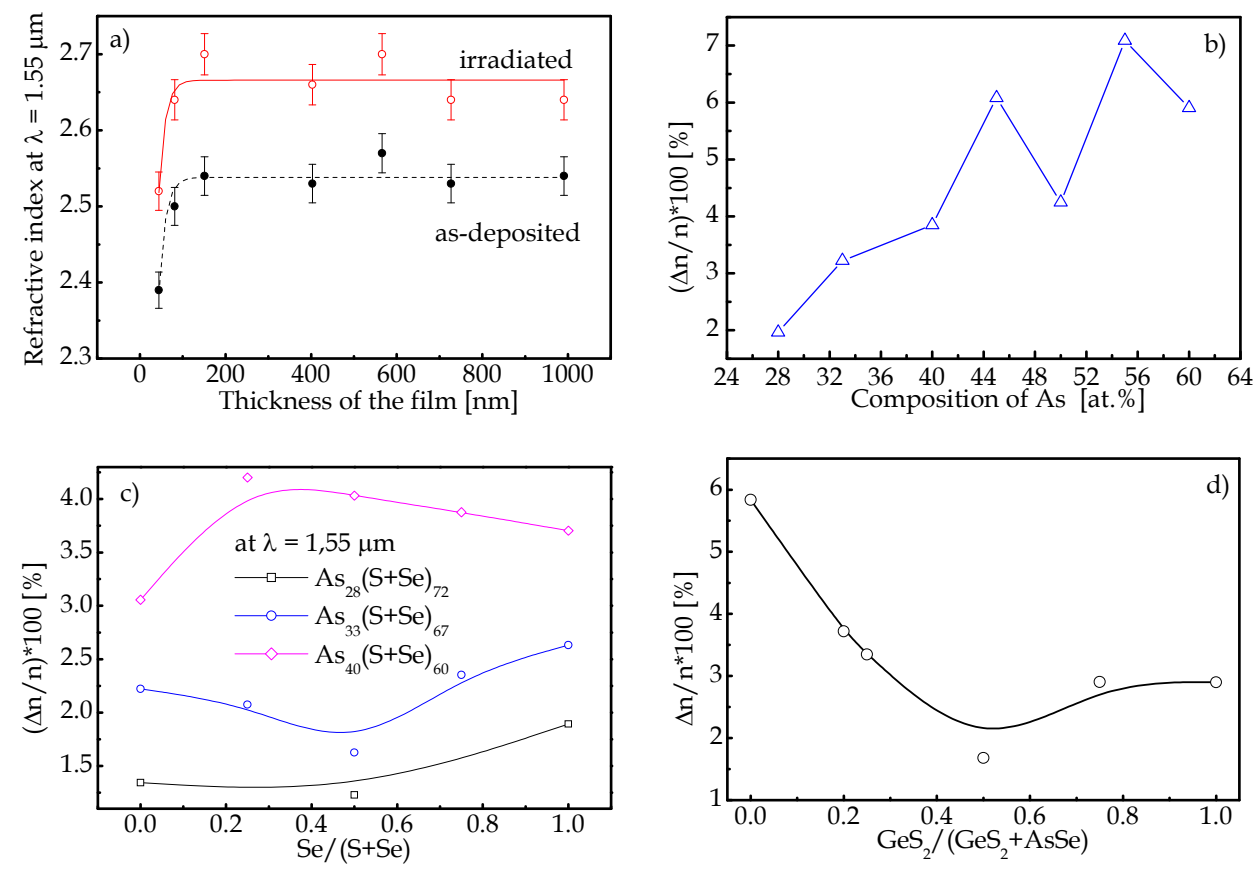

Fig. 2. a) Refractive index (at $\lambda=1.55 \mu \mathrm{m}$ ) of as-deposited and light irradiated films of AsSe, depending on the thickness and absolute relative (to the as-deposited) refractive index change after exposure of thin films from b) As-Se, c) As-S-Se and d) As-S-Se-Ge systems

As seen from Fig. 2, the photostimulated refractive index changes can reach up to $7 \%$ in the system As-Se (fig. 2b), up to $4 \%$ in the system As-S-Se (fig 2 c) and up to $5.8 \%$ in As-S-Se-Ge system (fig. 2d). The data, presented in fig. 2 is a confirmation of the well-known fact that the sensitivity of As-containing chalcogenide films increases with the addition of arsenic. Though a tendency is observed for enhancing the photosensitivity of the coatings with the increase of the selenium in the As-S-Se system, the refractive index change is poorly influenced by the substitution of Se for sulphur. For the compositions within As-S-Se-Ge system (fig. 2d), obtained by co-evaporation of AsSe and $\mathrm{GeS}_{2}$ - the details of which were published elsewhere (Tasseva et al., 2005) - it can be concluded that films enriched in AsSe undergo higher photoinduced changes. The poorest is the sensitivity of the coatings, containing equal fractions 
AsSe and $\mathrm{GeS}_{2}(50 \%)$. The lower sensitivity of the $\mathrm{GeS}_{2}$ films in respect to the AsSe ones and in general to the bi-component As-containing films is justified by the fact that the tetrahedral structural units forming the amorphous network of the Ge-containing glasses are with a greater volume and therefore are hardly reoriented in comparison with the structural units of As-containing glasses (Raptis et al., 1997). The microhardness measurements, presented in our previous work (Tasseva et al., 2005) come also to support that suggestion. At this point it should be emphasized the result from our investigation that the refractive index value is not affected by the thickness of the film in the range $80-1000 \mathrm{~nm}$ (fig. 2a). The deviation from the plateau observed for the film of $40 \mathrm{~nm}$ thickness is possibly attributed to voids due to the sooner interruption of the deposition process, depriving the initial formations of the possibility to grow as an integral coating. The possibility to produce films with invariable refractive index still varying their thickness has a special importance for the fabrication of multilayered structures, as would be seen in the next sections.

Further, the discussed possibilities to modify the refractive index either by exposing the coatings to light or simply changing their composition within a chalcogenide system are utilizable in the production of focusing elements - microlenses or diffraction gratings (Wágner \& Ewen, 2000; Saithoh et. al., 2002; Kovalskiy et al., 2006; Eisenberg et al., 2005; Teteris \& Reinfelde, 2004; Arsh et. al. 2004; Freeman et. al. 2005; Beev et. al. 2007; Vlaeva et. al. 2011). The phenomenon of total internal reflection staying at the basis of applications such as optical fibers or planar waveguides (Su et. al. 2008; Liao et. al. 2009; Conseil et. al. 2011; Savović \& Djordjevich, 2011, Ung \& Skorobogatiy 2011, Rowlands et. al. 2010, Ganjoo et al. 2006; Riley et al. 2008), could also benefit from the opportunity of retaining interface losses low when creating refractive index profile in compatible materials.

Let us now consider the non-linear response of the chalcogenide medium to intense light with photon energies lower than the optical band-gap. We know that two-photon absorption will be involved in the interband transitions in that case (Boyd, 2003). One of the associated effects is the induction of a non-linear refractive index, $n_{2}[e s u]$ or $\gamma\left[\mathrm{m}^{2} / \mathrm{W}\right]$ that gives the rate at which the intensity dependent refractive index $n^{\prime}$ changes with increasing light intensity, $I$ :

$$
n^{\prime}=n+\gamma=n+\frac{n_{2}}{2}|E|^{2}
$$

where $n$ is the linear, weak-field refractive index, $I$ - the intensity and E denotes the strength of the applied optical field. A detailed discussion on the origin of the nonlinear response in chalcogenides is published in (Bureau et al., 2004, Zakery \& Elliott, 2007, etc). The electron shells of the chalcogens are such that favor the induction of polarization under strong electromagnetic field that is, in general, directly associated with the nonlinearity (Boyd, 2003). It is discussed in (Bureau et al., 2004) that the coordination of the chalcogen atoms is always pseudo-tetrahedral, consisting of two bonding and two anti-bonding electron pairs. One consequence of the presence of the unpaired electrons is that they occupy levels in the energy diagram, located between the bonding and non-bonding levels, significantly lowering in that way the optical band gap. The latter strongly influences the non-linear refractive index, according to the formula developed by Sheik-Bahae et al. (1990):

$$
\gamma=K \frac{\hbar c \sqrt{E_{p}}}{2 n^{2} E_{g}^{o p t 4}} G_{2}\left(\hbar \omega / E_{g}^{o p t}\right)
$$


where $\mathrm{E}_{\mathrm{p}}=21 \mathrm{eV}, \mathrm{K}$ is found to be $3.1 \times 10^{-8}$ in units such that $\mathrm{E}_{\mathrm{p}}$ and $\mathrm{E}_{\mathrm{g}} \mathrm{opt}$ are measured in $\mathrm{eV}$, and $\gamma$ is measured in $\mathrm{m}^{2} / \mathrm{W}, \mathrm{h}$ is the Dirac's constant, $\mathrm{c}$ the speed of light in vacuum and $G_{2}$ - a universal function:

$$
G_{2}(x)=\frac{-2+6 x-3 x^{2}-x^{3}-\frac{3}{4} x^{4}-\frac{3}{4} x^{5}+2(1-2 x)^{3 / 2} \Theta(1-2 x)}{64 x^{6}}
$$

where $\Theta$ is the Heaviside step function. $n_{2}$ and $\gamma$ are related by:

$$
n_{2}[e s u]=\frac{c n}{40 \pi} \gamma[S I]
$$

Originally developed for crystalline materials, Eq. 2 was shown to be applicable as a rough approximation as well for glasses (Tanaka, 2007), providing with a possibility for calculation of the dispersion of the nonlinear refractive index. In the same approximation, the two photon absorption, $\beta$, defined by $\alpha=\alpha_{0}+\beta I$ (where $\alpha_{0}$ is the linear absorption coefficient of the medium), can be expressed:

$$
\beta=K \frac{\sqrt{E_{p}}}{n^{2} E_{g}{ }^{o p t 3}} F_{2}\left(2 \hbar \omega / E_{g}{ }^{o p t}\right)
$$

where

$$
F_{2}(2 x)=\frac{(2 x-1)^{3 / 2}}{2 x^{5}} \text { for } 2 x>1
$$

and $\mathrm{F}_{2}(2 \mathrm{x})=0$ otherwise. That means that two photon absorption may occur for photon energies higher than at least half of the optical band-gap. It was shown (Mizrahi, 1989) that high values of $\beta$, that are likely to accompany the high values of the nonlinear refractive index, $\gamma$, would impose strong limitations upon the applicability of any third order nonlinear material. Qualitatively, that limitation would be expressed through a simple criterion set upon the so called figure-of-merit (FOM). For the effective operation of a given nonlinear device, the inequality should be observed:

$$
F O M=\frac{2 \beta \lambda}{\gamma}<1
$$

The above criterion implies that when optimizing chalcogenide compositions in order to enhance devices performance, we should carefully consider the trade-off between high nonlinearity and low optical losses due to two photon absorption. Following below, the results are depicted from the calculations of two photon absorption, nonlinear refractive index and FOM for thin films from $\mathrm{As}_{2} \mathrm{~S}_{3}, \mathrm{As}_{2} \mathrm{Se}_{3}$ and $\mathrm{GeS}_{2}$ (Fig. 3).

Chalcogenides, as suggested in table 1, offer a nonlinear refractive index up 700 times higher than that of fused silica, simultaneously detaining low two photon absorption, i.e. FOM. It is seen that small additions of silver (the thickness of the silver layer used for the process of photodiffusion, as reported elsewhere (Tasseva et al., 2010), was $25 \mathrm{~nm}$ ) increase 3 times $\gamma$ 
still keeping low values of the two photon absorption. The values of the non-linear refractive index predicted for thin As-S-Se films are commensurable with those measured for bulk samples (Cardinal et al., 1999). The ultrafast response, i.e. the induction of nonlinear refractive index in chalcogenides exposed to the influence of strong electromagnetic field could be explained in the terms of the electronic structure of the glasses, considering ionization of the atom and distortion of the electron orbits (Liu et al., 2005).
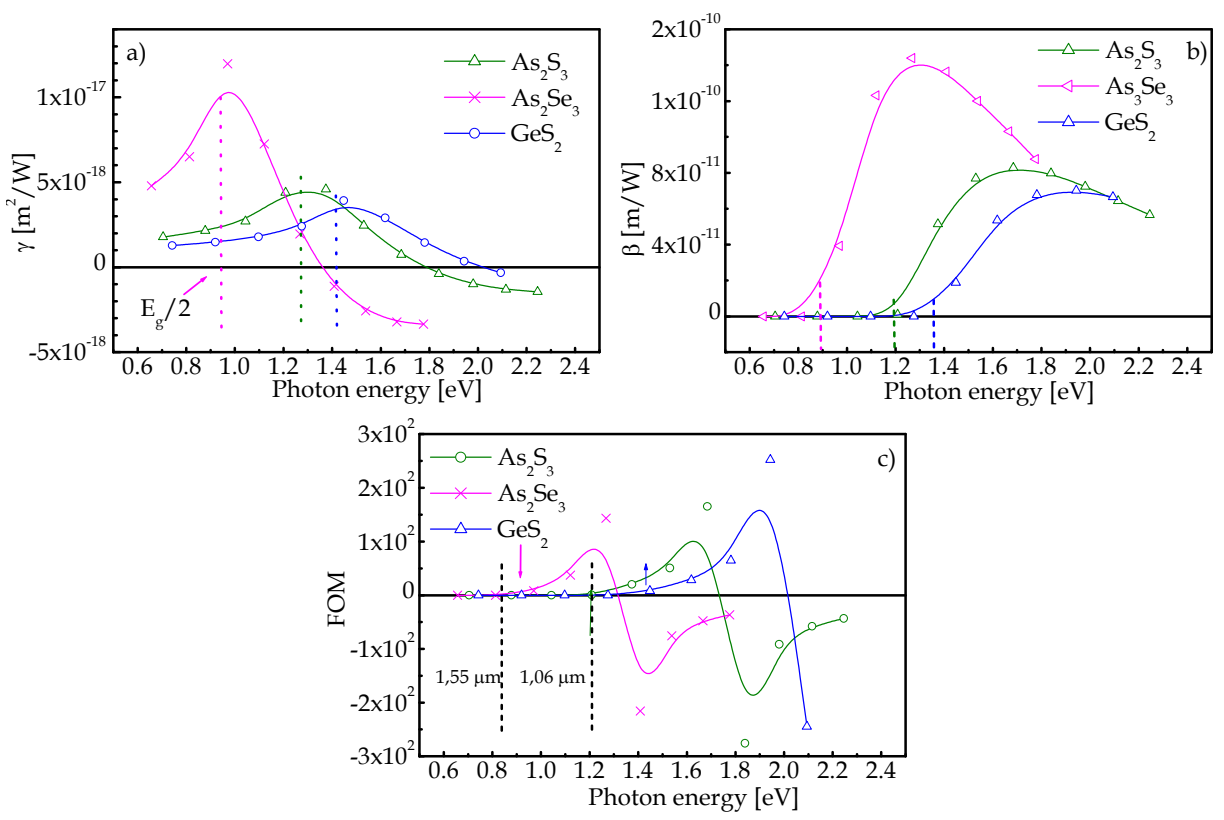

Fig. 3. Dispersion of the a) nonlinear refractive index, b) two photon absorption and c) FOM of thin chalcogenide films, calculated from eqs (2), (5) and (7)

\begin{tabular}{|c|c|c|c|}
\hline $\begin{array}{c}\text { Composition of the } \\
\text { thin film }\end{array}$ & $\begin{array}{c}\gamma\left[\mathrm{m}^{2} / \mathrm{W}\right] \\
\times 10^{-18}\end{array}$ & $\gamma / \gamma \mathrm{SiO}_{2}$ & FOM \\
\hline $\mathrm{As}_{40} \mathrm{~S}_{60}$ & 1.96 & 71 & 0 \\
\hline $\mathrm{As}_{40} \mathrm{Se}_{60}$ & 6.32 & 231 & 0 \\
\hline $\mathrm{As}_{40} \mathrm{~S}_{30} \mathrm{Se}_{30}$ & 3.58 & 131 & 0 \\
\hline $\mathrm{As}_{39.2} \mathrm{Se}_{55.1} \mathrm{Ag}_{5.7}$ & 19.1 & 697 & 0 \\
\hline $\mathrm{As}_{41} \mathrm{Se}_{28} \mathrm{~S}_{26} \mathrm{Ge}_{5}$ & 4.46 & 163 & 0 \\
\hline $\mathrm{Ge}_{33} \mathrm{~S}_{67}$ & 1.47 & 54 & 1 \\
\hline
\end{tabular}

Table 1. Nonlinear refractive index values, $\gamma$ and FOM for low-loss thin chalcogenide films of various compositions at $\lambda=1.55 \mu \mathrm{m}$

In the process of selection of chalcogenide compositions for optimized photonic applications, as discussed in the lines above, one should be careful in tailoring the properties of the materials. It should be taken account for transparency of the films in the designation spectral region, high nonlinearities and low nonlinear absorption, high photosensitivity. 


\section{Theory}

\subsection{Short description of theory of photonic crystals}

Photonic crystals are artificial structures usually comprising two media with different dielectric permittivity arranged in periodic manner with periodicity of the order of wavelength for the visible spectral range. Generally photonic crystals are divided into one-, two- or three dimensional PhC referred to as 1D, 2D and 3D PhC, depending on the dimensionality of the periodicity.

Photonic crystals occur in nature. Spectacular examples can be found in the natural opal, multilayered structures of pearls, flashing wings of some insects etc. A close inspection with an electron microscope shows that many species of butterflies and beetles have photonic crystal structures in some part of their bodies, resulting in a variety of optical effects such as structural colours, for example.

Although photonic crystals have been studied in one form or another since 1887, the term "photonic crystal" appeared about 100 years later, after Eli Yablonovitch and Sajeev John published two papers on photonic crystals (see Yablonovitch, 1987, John, 1987). It is very important to note that the periodicity is not a sufficient condition for a certain structure to be called photonic crystal. There is another requirement, namely the optical contrast, i.e. the difference between dielectric permittivity of the two constituent media, to be high enough (Yablonovitch, 2007).

One of the most striking features of photonic crystals is associated with the fact that if suitably engineered, they may exhibit a range of wavelengths over which the propagation of light is forbidden for all directions. The band of forbidden wavelengths is commonly referred to as "photonic band gap-PBG" and as "complete (or 3D) photonic band gap" if it is realized for all light propagation directions. These photonic bands enable various applications of $\mathrm{PhC}$ in linear, non-linear and quantum optics.

As mentioned above, the concept of 3D PBG materials was independently introduced by Yablonovitch (1987) and John (1987). Extensive numerical calculations conducted few years later (Ho et al. 1990) shown that 3D structures with a certain symmetry do indeed exhibit complete PBG. The "ideal" photonic crystal, defined as the one that could manipulate light most efficiently, would have the same crystal structure as the lattice of the carbon atoms in diamond. It is clear that diamonds cannot be used as photonic crystals because their atoms are packed too tightly together to manipulate visible light. However, a diamond-like structure made from appropriate material with suitable lattice constant would create a large "photonic bandgap". The first 3D photonic crystal was fabricated in 1991 in the group of Eli Yablonovitch (Yablonovitch et al., 1991) and is called Yablonovite. It had a complete photonic band gap in the microwave range. The structure of Yablonovite had cylindrical holes arranged in a diamond lattice. It is fabricated by drilling holes in high refractive index material.

Two-dimensional structures with a complete photonic band gap are neither known, nor likely to occur. Nevertheless, there is a growing scientific interest in 2D structures. The scientific efforts are focused on introduction of functional defects in 2D structures in order to realize waveguide structures (Brau et al., 2006). 
The widely accepted concept for a one-dimensional photonic crystal is a quarter-wave stack of alternating low- and high-refractive index layers (Joanopoulus et al., 1997). For a wave propagating normally to the stack (zero angle of incidence), a one-dimensional photonic band gap exists that is shifted towards smaller wavelengths with increasing the incident angle. Considering all possible angles and polarizations, one can mistakenly conclude that a 1D structure has no three-dimensional photonic band gap. Fortunately, it has been shown that if the optical contrast (the difference in dielectric permittivity between stack constituents) and number of the layers are sufficiently high, an omnidirectional (OD) reflectance band could be open (reflectance of the stack is close to unity for all incident directions and polarization of light) (Fink et al., 1998). As it will be shown in the next section, there are special requirements for low and high refractive index values of the two media of the stack.

Here we will give some details of calculation of the photonic band gap in the case of $1 \mathrm{D}$ PhC. The calculation methods for 2D and 3D cases are not presented here because they are out of the scope of this chapter. Very comprehensive description can be found in (Sakoda K., 2005) for example.

As already mentioned, 1D PhC can be realized by deposition of alternating high and low refractive index layers with a quarter-wave optical thicknesses. If the refractive index and thicknesses of the materials are represented by $n_{i}$ and $d_{i}$, where the subscripts $i$ is $H$ or L for high and low refractive index material, then the characteristic matrices $M_{P}$ and $M_{S}$ of each layer for $\mathrm{p}$ and $\mathrm{s}$ - polarization can be written in the form:

$$
M_{P}=\left(\begin{array}{cc}
\cos \Delta_{i} & \frac{-i n_{i} \sin \Delta_{i}}{\cos \theta_{i}} \\
\frac{-i \cos \theta_{i} \sin \Delta_{i}}{n_{i}} & \cos \Delta_{i}
\end{array}\right) \text { and } M_{S}=\left(\begin{array}{cc}
\cos \Delta_{i} & \frac{-i \sin \Delta_{i}}{n_{i} \cos \theta_{i}} \\
-i n_{i} \cos \theta_{i} \sin \Delta_{i} & \cos \Delta_{i}
\end{array}\right),
$$

In eq.8 $\Delta_{i}=2 \pi n_{i} d_{i} \cos \theta_{i} / \lambda$ is the optical phase thickness of the layer and $\theta_{i}$ is connected with the angle of incidence $\theta_{0}$ by the Snell-Decarte's law $n_{0} \sin \theta_{0}=n_{i} \sin \theta_{i}$, where $n_{0}$ is the refractive index of incident medium.

The multilayered stack composed of $q$ pairs of high $(\mathrm{H})$ and low $(\mathrm{L})$ refractive index layers, is presented by the matrix multiplication:

$$
\begin{gathered}
Q_{P}=\left(n_{S} / n_{0}\right)^{*} I^{*} H^{*}(L H) \mathrm{q}^{*} S, \text { for p-polarization } \\
Q_{S}=0.5^{*} I^{*} H^{*}(L H) \mathrm{q}^{*} S, \text { for s-polarization, }
\end{gathered}
$$

where the sign "*” denotes matrix multiplication, the matrices $H$ and $L$ are the characteristic matrices $M_{P}$ and $M_{S}$ for high and low refractive index materials; $I$ and $S$ are the characteristic matrices of the two surrounding media, usually air and substrate with refractive indices $n_{0}$ and $n_{\mathrm{s}}$, respectively:

$$
I_{P}=\left(\begin{array}{cc}
1 & \frac{-n_{0}}{\cos \theta_{0}} \\
1 & \frac{-n_{0}}{\cos \theta_{0}}
\end{array}\right), I_{S}=\left(\begin{array}{cc}
1 & \frac{-1}{n_{0} \cos \theta_{0}} \\
1 & \frac{1}{n_{0} \cos \theta_{0}}
\end{array}\right), S_{P}=\left(\begin{array}{cc}
1 & 1 \\
\frac{-\cos \theta_{S}}{n_{S}} & \frac{\cos \theta_{S}}{n_{S}}
\end{array}\right) \text { and } S_{S}=\left(\begin{array}{cc}
1 & 1 \\
-n_{S} \cos \theta_{S} & n_{S} \cos \theta_{S}
\end{array}\right)
$$


where the angle $\theta_{s}$ is associated with $\theta_{0}$ by the Snell-Decarte's law $n_{0} \sin \theta_{0}=n_{s} \sin \theta_{s}$. Note in Eqs 9 and 10 that for high reflectance the stack should be terminated with high refractive index layer.

Transmittance and reflectance of the stack are finally obtained from the respective matrix elements $Q(i, j)$ :

$$
\begin{gathered}
T_{P}=\frac{n_{s} \cos \theta_{s}}{n_{0} \cos \theta_{0}}\left|\frac{1}{Q_{P}(1,1)}\right|^{2} \text { and } T_{S}=\frac{n_{s} \cos \theta_{s}}{n_{0} \cos \theta_{0}}\left|\frac{1}{Q_{s}(1,1)}\right|^{2} \\
R_{P}=\left|\frac{Q_{P}(2,1)}{Q_{P}(1,1)}\right|^{2} \text { and } R_{S}=\left|\frac{Q_{S}(2,1)}{Q_{S}(1,1)}\right|^{2}
\end{gathered}
$$

The short and the long wavelength edges of the band are function of $n_{H}, n_{L}$ and the angle of incidence $\theta$. They are calculated according to (Kim et. al, 2002) and are presented in Fig. 4a. Fig. 4 b,c and d presents the reflectance of the stack for $p$ and s-polarized light incident at angles of $0,45^{\circ}$ and $85^{\circ}$ as a function of the wavelength calculated from Eqs 12 and 13. It is seen that for higher incident angles the band shifts towards smaller wavelengths becoming wider for s-polarization and narrower for p-polarization. The shaded area in fig. 4 indicates the omnidirectional reflectance (ODR) band that is the spectral area of high reflectance for all incident angles and polarization types. It is seen that ODR band opens between short wavelength edge for $0^{\circ}$ and long wavelength edge for p-polarization at incident angle of $90^{\circ}$.

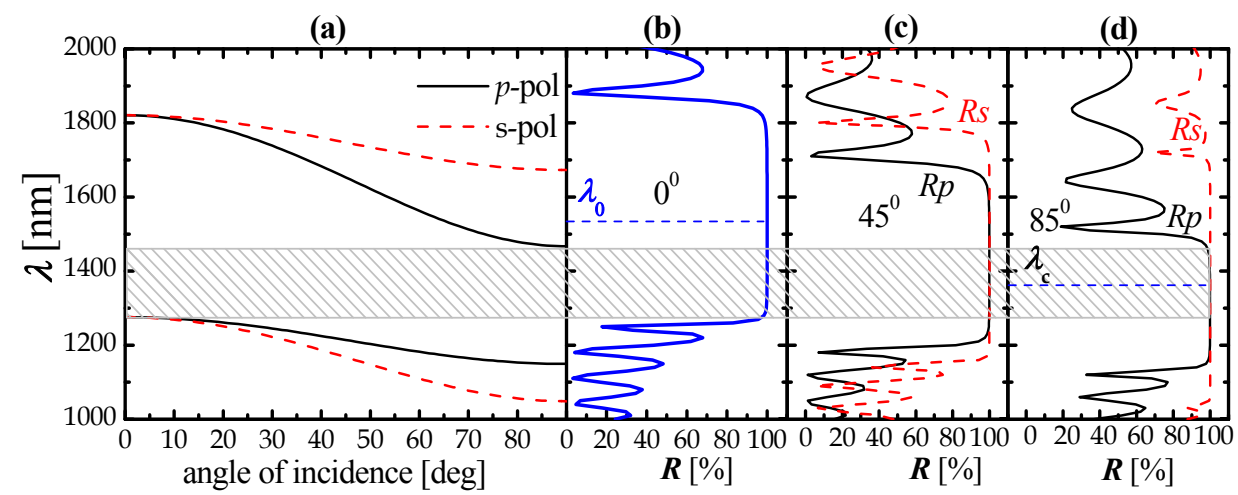

Fig. 4. a) Reflection band edges for both polarizations as a function of incident angle;

Reflectance of the stack as a function of wavelength for incident angles of b) $0^{\circ}$, c) $45^{\circ}$ and d) $85^{\circ}$. The shaded area represents the ODR band.

The short and long wavelength edges of ODR band can also be expressed explicitly as (Kim et. al., 2002):

$$
\lambda_{\text {short }}^{O D R}=\frac{\pi}{2}\left[\cos ^{-1}\left(-\frac{n_{H}-n_{L}}{n_{H}+n_{L}}\right)\right]^{-1}
$$




$$
\lambda_{\text {long }}^{\text {ODR }}=\frac{\pi}{4}\left(\frac{n_{L} \sqrt{n_{H}^{2}-n_{0}^{2}}+n_{H} \sqrt{n_{L}^{2}-n_{0}^{2}}}{n_{H} n_{L}}\right)\left[\cos ^{-1}\left(\frac{n_{H}^{2} \sqrt{n_{L}^{2}-n_{0}^{2}}-n_{L}^{2} \sqrt{n_{H}^{2}-n_{0}^{2}}}{n_{H}^{2} \sqrt{n_{L}^{2}-n_{0}^{2}}+n_{L}^{2} \sqrt{n_{H}^{2}-n_{0}^{2}}}\right)\right]^{-1}
$$

Knowing $n_{H}$ and $n_{L}$ it is easy to calculate the width and position of ODR band using eqs. 14 and 15. It was shown (Kim et. al., 2002) that as higher is the optical contrast between the stack's constituents as wider is the ODR band. It is interesting to note that the smallest value of $n_{H}$ for ODR to be opened is 2.264 (Kim et. al., 2002). It is clear from eqs 14 and 15 that the lowest refractive index for existence of ODR band can be calculated at a fixed $n_{H}$. For $n_{H}=2.264$ the lowest $n_{L}$ is 1.5132 , i.e the smallest optical contrast $\Delta n$ is around 0.75 .

From material and technological viewpoint, there are various materials and deposition methods suitable for successful preparation of quarter-wave stacks with good optical contrast resulting in wide reflectance band with high reflectance value. But for achieving ODR band low and high refractive index materials should be carefully chosen to fulfil the additional requirements $-n_{H}>2.264$ and $\Delta n \sim 0.75$.

One good opportunity is combining calcogenide glasses $\left(n_{H}>2.3\right.$ at $1550 \mathrm{~nm}$, see Fig. 1) and polymer layer $\left(n_{L} \sim 1.5-1.7\right)$. Quarter-wave stacks from $\mathrm{As}_{33} \mathrm{Se}_{67}\left(n_{H}=2.64\right), \mathrm{Ge}_{20} \mathrm{Se}_{80}$ $\left(n_{H}=2.58\right)$ and $\mathrm{Ge}_{25} \mathrm{Se}_{75}\left(n_{H}=2.35\right)$ as high refractive index materials and polyamide-imide films (PAI) $\left(n_{L}=1.67\right)$ and polystyrene (PS) $\left(n_{L}=1.53\right)$ as low refractive index materials are prepared (Kohoutek et. al., 2007a, Kohoutek et. al., 2007b) exhibiting high reflection band around $1550 \mathrm{~nm}$. We prepared a quarter wave stack combining $\mathrm{As}_{2} \mathrm{~S}_{3}$ with $n_{H}=2.27$ at 1550 $\mathrm{nm}$ and Poly(methyl methacrylate) (PMMA) polymer with $n_{L}=1.49$ thus achieving an optical contrast of about 0.78. Further it is shown that the addition of thin Au film with thickness of $50 \mathrm{~nm}$ as a layer close to the substrate in $\mathrm{Ge}_{33} \mathrm{As}_{12} \mathrm{Se}_{55}$ / PAI stack increases the width of ODR band three times (Ponnampalam et. al., 2008) ).

Another possibility for achieving ODR band is combining two suitably chosen chalcogenide glasses, i.e fabrication of all-chalcogenide reflectors. Combinations of Ge-S / Sb-Se (Kohoutek et al. 2009) with optical contrast of more than 1 and exposed $\mathrm{As}_{2} \mathrm{Se}_{3} / \mathrm{GeS}_{2}$ with optical contrast more than 0.8 have been already realized. (Todorov et al. 2010b).

\subsection{Factors which influence the properties and quality of 1D photonic crystals}

In section 3.1 it was shown that both the optical contrast between the two component of 1D PhC and $n_{H}$ values are factors that influence the width of the omnidirectional reflectance band. Here we will show that the number of the layers and small optical losses due to absorption or scattering are additional factors that should be considered during the design of an OD reflector.

Fig. 5 presents the value of the reflectance band for normal light incidence as a function of the number of the layers in the stack and the ratio of their refractive indices. It is seen that the reflectance increases both with increasing the number of the layers and the ratio of their refractive indices. Besides, the lower optical contrast can be compensated to some extent by increasing the number of layers in the stack. For example if $n_{H} / n_{L}=1.8$ then 20 layers will be required for $100 \%$ reflectance whereas for $n_{H} / n_{L}=2.2$ only 14 layers will be sufficient. 
It is well known that during the fabrication of the stack deviations of both refractive indices and thicknesses of the layers from their target values may occur. Our calculations showed that the deviation of refractive index influences mostly the optical phase thickness of the $L$ layer, while the deviation in thickness from the target values is pronounced by changes in the phase thickness of the $H$-layer. If the error in $n$ is $\Delta n= \pm 0.02$, than the phase thickness $\Delta_{i}=2 \pi n_{i} d_{i} / \lambda$ changes with $1.3 \%$ for $i=L$ and $1 \%$ for $i=H$. The deviation of $5 \mathrm{~nm}$ in the thickness leads to $1.9 \%$ and $2.9 \%$ changes of phase thicknesses of low and high refractive index layers. Fig. 6 presents the influences of the error in thickness and small losses in the layers on the reflectance band for the particular case of $\mathrm{As}_{2} \mathrm{~S}_{3}$ /PMMA stack with target refractive indices $n_{H}=2.27, n_{L}=1.49$ and thicknesses $d_{H}=170 \mathrm{~nm}$ and $d_{L}=260 \mathrm{~nm}$. From Fig 6(a) it is seen that the alteration of thicknesses with $5 \mathrm{~nm}$ leads to the band shift of $44 \mathrm{~nm}$. The small absorption of the layers leads to decrease in $R$ of $0.5 \%$ for $k=0.001$ and 2.1 $\%$ for $k=0.005$. (Fig. $6(\mathrm{~b})$ ).

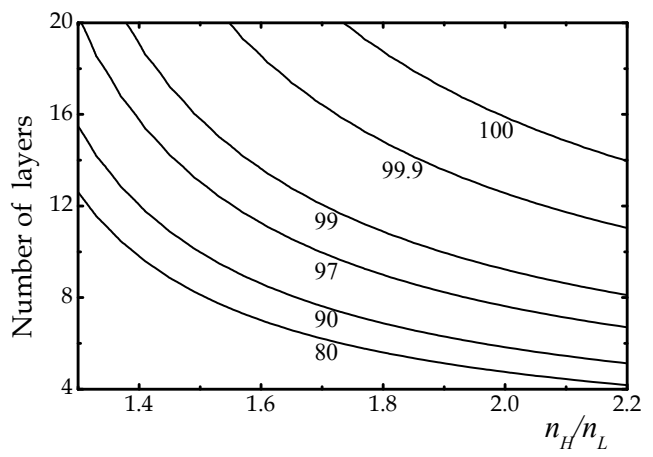

Fig. 5. Value of reflectance band for normal light incidence as function of number of the layers in the stack and ratio of their refractive indices
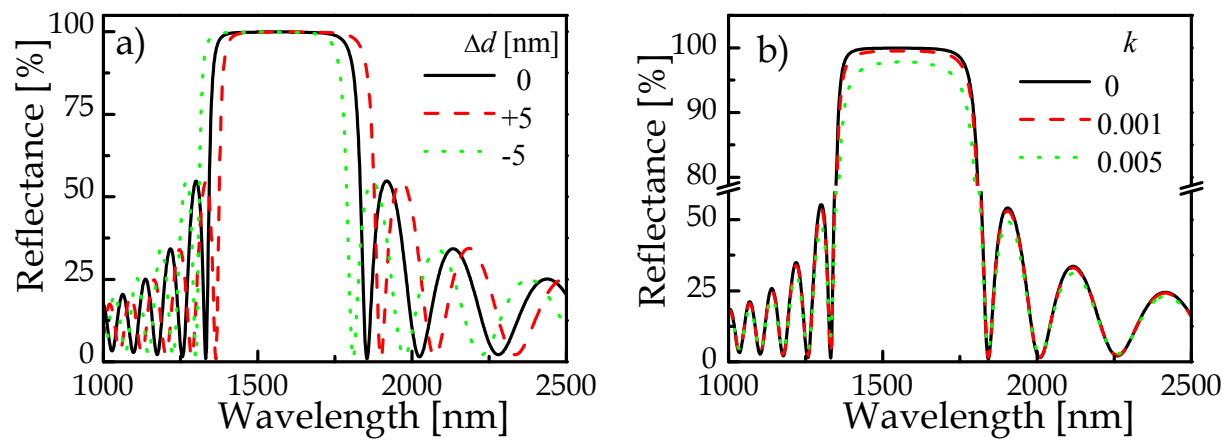

Fig. 6. a) Shift of reflectance band of $\operatorname{As}_{2} \mathrm{~S}_{3}\left(n_{H}=2.27, d_{H}=170 \mathrm{~nm}\right) / \operatorname{PMMA}\left(n_{L}=1.49, d_{L}=270\right.$ $\mathrm{nm}$ ) stack due to error of $5 \mathrm{~nm}$ in thicknesses; b) influence of small absorption of layers on the reflectance value. 
The comparison between the real and ideal 1D-PhC from $\mathrm{As}_{2} \mathrm{~S}_{3}$ / PMMA is presented in Fig. 7. It is seen that there is an insignificant shift between the reflectance bands of both structures. The difference of $1.1 \%$ between the measured and calculated reflectance can be due to slight absorption and scattering of the layers as well as to measurements errors. The most significant difference between the fabricated and simulated structures is in the side peaks. Note for example the first minima that are very high for the real structure and zero for the simulated one. Most probably this difference is due to random deviations of phase thicknesses of the constituent layers leading to violation of the conditions for destructive interference.

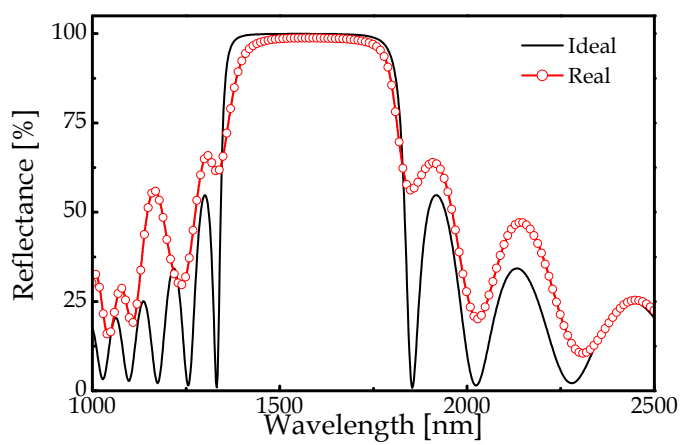

Fig. 7. Measured and simulated reflectance band of $\mathrm{As}_{2} \mathrm{~S}_{3} /$ PMMA stack

\section{Device fabrication}

\subsection{Methods for fabrications of PhC's}

In Section 3.1 it was mentioned that the widely accepted approach for production of $1 \mathrm{D}$ $\mathrm{PhC}$ is the alternating deposition of high and low refractive index materials with quarterwave thicknesses. Depending on the materials chosen, different deposition methods as vacuum condensation, spin and dip coating, pulsed laser deposition, sol-gel etc. are used. The experimental conditions for deposition thin films of 1D PhC is presented below in section 4.2.

The most widely recognized methods for preparation of $2 \mathrm{D}$ and $3 \mathrm{D}$ photonic crystals are colloidal self-assembly, direct laser writing and lithography with deep etching, that can be E-beam, X-ray or holographic lithography (Lopez, 2003).

Typical colloidal PhC are face centred 3D arrays of self assembled monodispersed silica or polymer microspheres with diameter from $200-2000 \mathrm{~nm}$. The sedimentation is often used for fabrication of thick samples, which are called bulk opals. Besides, deposition on vertical substrates with controlled moving meniscus (Egen et al., 2004) is used for thinner samples. Because the refractive index of silica and polymers spheres is around 1.5, the optical contrast of 0.5 is not sufficient for opening of a complete PBG. A post fabrication infiltration of colloidal crystals with high refractive index material is necessary. Following this strategy a colloidal crystals infiltrated with Si and Ge exhibiting complete PBG at wavelength of 1.5 $\mu \mathrm{m}$ are fabricated (A. Blanco et al., 2000 ). 
Direct laser writing method through multi-photon absorption is another method for producing 3D PhC. The light from the laser is focused on a small spot of the dye-doped polymer used as a recording medium. The energy of the laser excites the dye molecules that initiate a local polymerization in the spot thus changing the refractive index of the polymer in the illuminated spot. A spatial resolution of $120 \mathrm{~nm}$ is reported in the literature (Kawata et al., 2001). The problem is that the optical contrast is very small and infiltration of the structure is needed. Another possibility is using the laser writing in high refractive index material. Promising candidates are chalcogenide glasses, particularly $\mathrm{As}_{2} \mathrm{~S}_{3}$ that undergo changes in solubility upon exposure to light.

Conventional lithography and selective etching were used mainly for fabrication of 2D PhC. For producing 3D PhC a concept of layer-by-layer deposition has to be implemented that comprises repeated cycles of photolithography, wet and dry etching, planarization, and growth of layers (Blanco et. al., 2004).

The holographic lithography is very promising method enabling large-area defect-free 2D and 3D periodic structure to be produced in a single-step. In holographic lithography the sensitive medium (a photoresist) is exposed to a multiple-beam interference pattern (for $\mathrm{N}$ dimensional structures at least $\mathrm{N}+1$ beams are required) and subsequently developed, producing a porous structure. The interbeam angles and polarizations and the number of beams determine the type of symmetry of the recorded structures. It has been theoretically shown that all 14 Bravais lattices could be produced (Cai et. al., 2002). Usually SU-8 photoresist with refractive index of around 1.67 is used. A recognized drawback is the need for infiltration of the produced structure with high refractive index material. Otherwise the optical contrast is not sufficiently high for opening a complete photonic band. Difficulties such as optical alignment, vibrational instability, and reflection losses on the interface air/photoresist further complicate the recording processes. One possibility for overcoming the problem is rotating the sample between two consecutive exposures (Lai et. al., 2005). The second approach is implementation of specially design diffraction mask that provides the required number of beams with correct directions and polarizations reducing the alignment complexity and vibration instabilities in the optical setup (Divlianski et. al., 2002).

Two-dimensional structures have already been fabricated in chalcogenide glasses using holographic lithography (Feigel et. al., 2005; Su et. al., 2009). To the best of our knowledge holographic lithography has not been used yet for fabrication of 3D PhC from chalcogenide glasses. The three dimensional wood-pile photonic crystals made in chalcogenide glasses are fabricated by direct laser writing (Nicoletti et. al., 2008) or through layer-by-layer deposition (Feigel et. al., 2003).

\subsection{Experimental procedure for deposition of 1D photonic crystals}

In the present work we used the concept of layer-by-layer deposition of quarter-wave stacks of alternating suitably chosen films with low and high refractive indices for producing of one-dimensional photonic crystals.

The bulk chalcogenide glass was synthesized in a quartz ampoule by the method of melt quenching from elements of purity $99.999 \%$. The chalcogenide layers were deposited by thermal evaporation at deposition rate of $0.5-0.7 \mathrm{~nm} / \mathrm{s}$. The X-ray microanalysis showed that the film composition is close to that of the bulk samples (Todorov et al., 2010b). 
The multilayer structures formed only from chalcogenide sublayers were produced in one cycle of thermal evaporation using two sources - $\mathrm{As}_{2} \mathrm{Se}_{3}$ and $\mathrm{GeS}_{2}$. After deposition the samples were exposed in air to a mercury lamp $\left(20 \mathrm{~mW} . \mathrm{cm}^{-2}\right)$.

Multilayered stacks from chalcogenide glass and organic polymer comprising 19 layers are prepared by alternating vacuum evaporation of $\mathrm{As}_{2} \mathrm{~S}_{3}$ with target thickness of $170 \mathrm{~nm}$ and spin coating of PMMA with target thickness of $260 \mathrm{~nm}$. The stock solution of the polymer was prepared by dissolution at ambient temperature of one gram of PMMA (Poly (methyl methacrylate)) in $10 \mathrm{ml}$ of Dichloroethane (Aldrich) using magnetic stirrer for accelerating the process. The polymer films with different thicknesses are obtained by the method of spin coating using the stock solution further diluted by adding dichloroethane. Polymer layers with thicknesses of $260 \mathrm{~nm}$ are obtained by dripping a drop of $0.5 \mathrm{ml}$ of $2.2 \mathrm{wt} \%$ polymer solution on the preliminarily cleaned substrate. The speed and duration of spinning were $2000 \mathrm{rpm}$ and $30 \mathrm{~s}$. To remove the extra solvent the samples are annealed for 30 minutes at temperature of $60^{\circ} \mathrm{C}$.

\subsection{Optical methods for control and characterization of thin films for photonic crystals fabrication}

It is known that thin film's thickness can significantly affect their optical constants. In literature there is no unanimity about the dependence of the refractive index of thin chalcogenide films on their thickness (Abdel-Aziz et al. 2001). In photonic crystals it is necessary that the thin films are deposited with an exact optical thickness, (nd). For example, when a thin chalcogenide film is a part of a quarterwave stack and its refractive index has a value between 2.00 and 3.60 (see Fig.1), the thickness of the sublayers must be $110-193 \mathrm{~nm}$ for the working wavelength $\lambda=1550 \mathrm{~nm}$.

The optical constants of thin films are usually determined by optical methods as spectrophotometry, prism-coupling technique and ellipsometry. We have demonstrated that the spectrophotometric and ellipsomeric methods offer a good accuracy for determination of the optical parameters of thin chalcogenide films from $\lambda / 30$ to $2 \lambda$ ( $\lambda$ is working wavelength) (Konstantinov et al. 1998, Babeva et al. 2001, Todorov et al. 2010a). Results on the reflectance response of photonic crystals from chalcogenide glass/polymer (DeCorby et al., 2005; Kohoutek et al., 2007a) or chalcogenide glass/chalcogenide glass, e.g. $\mathrm{GeS}_{2} / \mathrm{Sb}_{2} \mathrm{Se}_{3}$ (Kohoutek et al., 2009b) by variable angle spectroscopic ellipsometry have been reported.

In the present work optical transmittance and reflectance measurements at normal incidence of light beam were carried out in the spectral range from 350 to $2500 \mathrm{~nm}$ using an UV-VIS-NIR spectrophotometer (Cary 05E, Australia). Reflectance measurements at oblique incidence of linearly polarized light were performed with VASRA (Variable Angle Specular Reflectance Accessory). For polarizing the incident radiation, a high quality Glan-Taylor polarizer is used that provides an extremely pure linear polarization with a ratio 100 000:1. The computer controlled stepper motor of the VASRA accessory ensures reproducible adjustment of the incident angle with an accuracy $\Delta \theta= \pm 0.25^{\circ}$ (according to the Cary Operation Manual). A self-made reference Al-mirror, whose preparation and characterization are described in details elsewhere (Babeva et al., 2002), is used as a standard mirror. 


\section{Results and discussion}

\subsection{Optical properties of thin chalcogenide films}

In this part the optical properties are presented of real multilayered structures consisting of alternating layers chalcogenide-chalcogenide glass and chalcogenide glass-organic polymer. The possibility of tuning their properties under external factors such as annealing or strong electric field is examined.

As it is mentioned in section 3.2, the knowledge of the optical properties of the single layers is important for the successful engineering of a multilayer structure. Firstly we have investigated the optical parameters of the single layers. The results of the investigation of the thickness dependence of the refractive indices of thin films from some basic chalcogenide glass formers $\mathrm{As}_{2} \mathrm{~S}_{3}, \mathrm{As}_{2} \mathrm{Se}_{3}$ and $\mathrm{GeS}_{2}$ are given in Fig. 8.

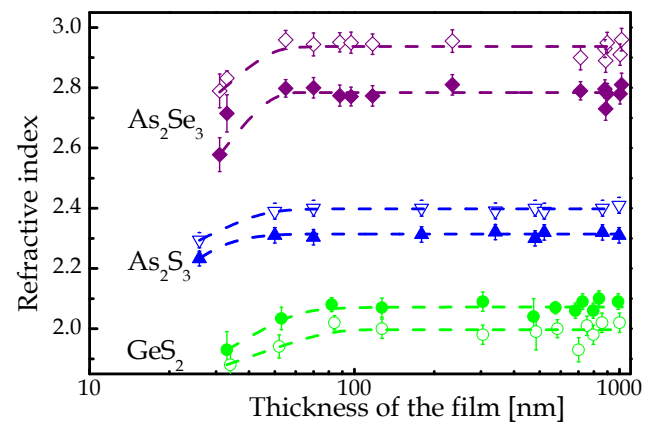

Fig. 8. Refractive index of $\mathrm{GeS}_{2}, \mathrm{As}_{2} \mathrm{~S}_{3}$ and $\mathrm{As}_{2} \mathrm{Se}_{3}$ thin films at $\lambda=1550 \mathrm{~nm}$ as a function of thickness before (solid symbols) and after irradiation (open symbols).

The Swanepoel's method (Swanepoel, 1983) was used for optical constants determination of the thin films with $\mathrm{d}>300 \mathrm{~nm}$ and a combination of double $(\mathrm{T}, \mathrm{R})$ and triple $(\mathrm{T}, \mathrm{R}, \mathrm{R})$ methods was applied in calculations for thinner layers $(\mathrm{d}<300 \mathrm{~nm})$ (Konstantinov et al., 1998; Babeva et al. 2001). The calculated values for optical parameters of thin films show that their refractive index is independent on the layer's thickness for $\mathrm{d}>50-70 \mathrm{~nm}$ (Fig. 8). The calculated values for the refractive indices of thin films with composition $\mathrm{As}_{2} \mathrm{Se}_{3}$ and $\mathrm{GeS}_{2}$ were 2.83 and $2.07(\lambda=1550 \mathrm{~nm})$, respectively. Through the addition of metal in $\mathrm{As}_{2} \mathrm{Se}_{3}$ such as $\mathrm{Ag}$ and $\mathrm{Cu}$ thin films with a higher refractive index can be produced (Ogusu et al., 2004). The Ag-As $\mathrm{Se}_{3}$ layer cannot be obtained by direct evaporation of the ternary Ag-As-Se glass since phase decomposition occurs. On the account of this, photodoping technique is used to produce As-As-Se film: evaporating Ag layer with a certain thickness on the $\mathrm{As}_{2} \mathrm{Se}_{3}$ layer, and exposing the stack to induce migration of the silver (Tasseva et al., 2010, Suzuki et al., 2005). We found a refractive index of 3.06 at $\lambda=1550 \mathrm{~nm}$ for thin $\mathrm{As}_{2} \mathrm{Se}_{3}$ film photodoped with 10 at \% Ag (Tasseva et al., 2010). The photosensitivity of the chalcogenides arises from structural rearrangements induced by the absorption of photons at energies near the optical band gap of the material (Shimakawa et al., 1995). These structural rearrangements lead to changes in the optical properties. The magnitude and sign of these photoinduced changes can be dependant on the chemical composition of the glasses (Tanaka et al., 1979) and on the 
processing history of the sample (Okuda et al., 1979). It is seen from Fig.8 that the arsenic containing thin chalcogenide films with compositions $\mathrm{As}_{2} \mathrm{~S}_{3}$ and $\mathrm{As}_{2} \mathrm{Se}_{3}$ demonstrate increasing of the refractive index up to 2.39 and 2.93 after exposure to light, respectively while for thin $\mathrm{GeS}_{2}$ layer $\mathrm{n}$ decreases to 2.03 .

Furthermore, these changes may be either reversible or irreversible. The irreversible changes result from light exposure or thermal annealing of as-deposited thin films in a non-equilibrium state (Biegelsen et al., 1980) while the reversible changes result from structural rearrangement leading from one quasi-stable state to another (Street, 1977, Biegelsen et al., 1980). In Fig. 9 the changes of the refractive index are shown of thin $\mathrm{As}_{2} \mathrm{Se}_{3}$ film after exposure and annealing. The as-deposited layer demonstrates an increase of the refractive index $(\Delta n=+0.14$ at $\lambda=1550 \mathrm{~nm})$ that is an expression of the photo-darkening effect. A reversible change of $\Delta n=-0.02$ after annealing at $160^{\circ} \mathrm{C}$ in vacuum was observed.

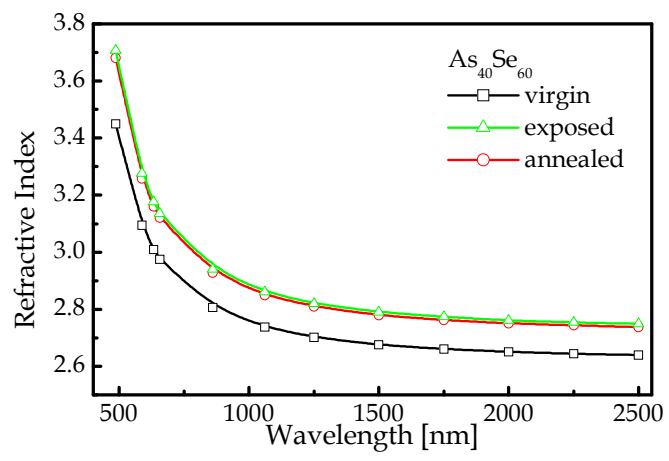

Fig. 9. Dispersion of the refractive index, $n$ of as-deposited, exposed and subsequently annealed at $160^{\circ} \mathrm{C}$ in vacuum thin $\mathrm{As}_{2} \mathrm{Se}_{3}$ film.

\subsection{Optical properties of a double layered structure and multilayered coatings}

Further, we use the data plotted in Fig. 8 for modelling of double- and multilayered structures. The reflectance spectrum of a double layered coating from $\mathrm{As}_{2} \mathrm{Se}_{3}$ and $\mathrm{GeS}_{2}$ (BK-7/ $\mathrm{As}_{2} \mathrm{Se}_{3} / \mathrm{GeS}_{2}$ ) was discussed in (Todorov et al. 2010b). Having determined the optical parameters and thickness of the single layers we calculated the theoretical reflectance spectrum of the complex structure using the equations from section 3.1. A good coincidence between the theoretical and measured spectrum of the double layered structure was obtained.

In Fig. 10 the measured transmittance and reflectance spectra at normal light incidence $\left(\theta=0^{\circ}\right)$ and angle $\theta=70^{\circ}$ of 19 layers quarter-wave structure from alternating $\mathrm{As}_{2} \mathrm{Se}_{3}$ and $\mathrm{GeS}_{2}$ layers deposited on a glass and on an absorbing Si wafer substrate are presented. The shift of the photonic band gap to shorter wavelengths with the increase of the angle of light incidence, discussed in section 3 , is clearly seen. 


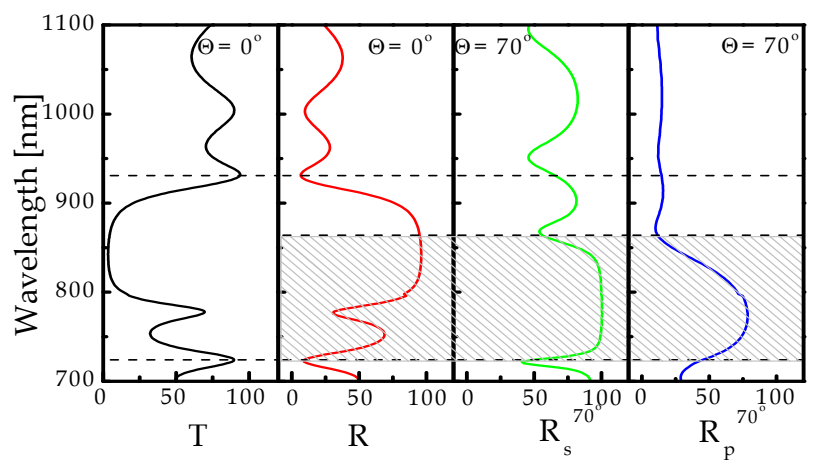

Fig. 10. Spectra of transmittance, $T$ and reflectance, $R$ of a multilayer coating on a glass substrate at normal incidence; and reflectance spectra at angle of light incidence $70^{\circ}$ for $\mathrm{p}-$ and s- light polarization. The shaded area represents the ODR band.

\subsection{Thermo-induced changes in chalcogenide glasses and tuning of the photonic band gap}

The ability to tune or modulate the optical properties of photonic crystals would increase their functionality and open up new possibilities for a variety of applications for integrated optics (Lee et al., 2007). Photosensitivity has been successfully utilized for post-tuning in 2D photonic crystals (Lee et al., 2007). In (Todorov et al., 2010b) we demonstrated a possibility of shifting the fundamental reflectance band of as-deposited multilayer $\mathrm{As}_{2} \mathrm{Se}_{3} / \mathrm{GeS}_{2}$ quarter-wave slab exposing it to light and thus inducing changes in both materials building the coating. It is seen from Fig. 1 that thin films from $\mathrm{Ge}-\mathrm{S}$ and As - Se systems ensure high optical contrast $\Delta n \sim 0.8$. The exposure to light leads to opposite effects in the thin films photodarkening in $\mathrm{As}_{2} \mathrm{Se}_{3}$ and photobleaching in $\mathrm{GeS}_{2}$ layers and increase of $\Delta n$ up to 1.0. The good knowledge of the photoinduced changes enabled a designed $50 \mathrm{~nm}$ expansion of the high reflectance band width. The presence of reversible changes in chalcogenide glasses allows production of photonic structures with dirigible optical properties.
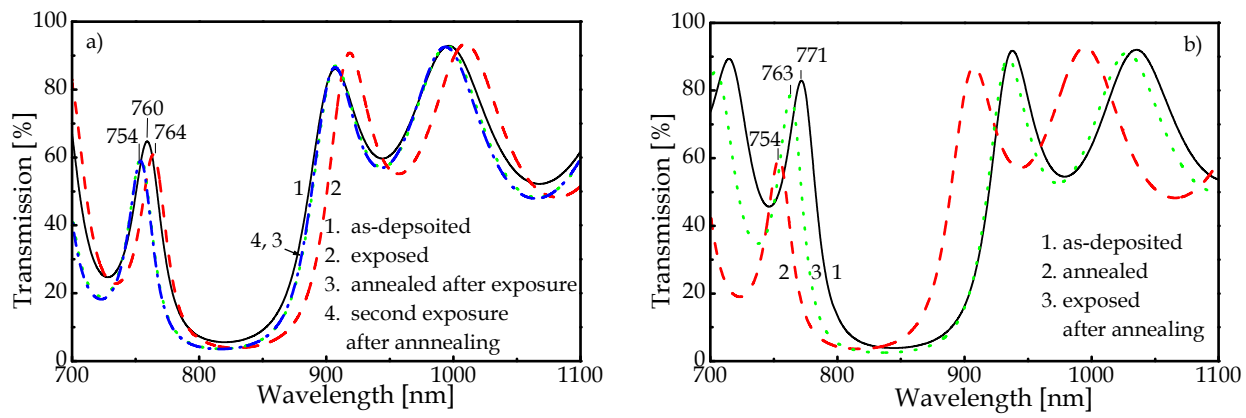

Fig. 11. Spectra of transmittance at normal light incidence of multilayer coating consisting of 19 alternating $\mathrm{As}_{2} \mathrm{Se}_{3}$ and $\mathrm{GeS}_{2}$ layers in different consequences of treatment: as-deposited exposed - annealed - exposed (a); and as-deposited - annealed - exposed (b). 
In Fig. 11 the changes in the transmittance spectra are presented of the multilayer coatings referred to in Fig. 10 after exposure to light from a mercury lamp and after annealing at $160^{\circ} \mathrm{C}$ in vacuum. The annealing temperature was selected to be with $20^{\circ} \mathrm{C}$ lower then the glass forming temperature for $\mathrm{As}_{2} \mathrm{Se}_{3}$ glass ( $\mathrm{Li}$ et al., 2002). The exposure to light leads to 17 $\mathrm{nm}$ or $30 \mathrm{~nm}$ red shift of the resonant band for as-deposited or annealed samples, respectively, at $\mathrm{T}=10 \%$. It is seen that light illumination results in expansion of the resonant band to longer wavelengths and parallel shift of the pass band in both as-deposited and thermally treated samples. The annealing of the samples causes the stop band to move to shorter wavelengths - with 14 and $28 \mathrm{~nm}(\mathrm{~T}=10 \%)$ for exposed and as-deposited samples, respectively. Due to the effect of thermobleching, observed in thin $\mathrm{As}_{2} \mathrm{Se}_{3}$ and $\mathrm{GeS}_{2}$ films (De Neufville et al. 1974, Tichy et al. 1993) the optical contrast between sublayers is changed after annealing. It is known that the reversible changes are increased with the increasing of the arsenic in the $\mathrm{As}_{\mathrm{x}} \mathrm{Se}_{100-\mathrm{x}}$ system for $\mathrm{x}>40$ at \% and allow making of many cycles between both states applying the light 'recording' and 'erasing' by annealing of the films (Lyubin, 1984). Unfortunately, the increase of the arsenic content for $40 \leq x \leq 60$ leads to a reduction of the refractive index (Petkov et al., 2009). Further investigations would involve the selection of suitable chalcogenide glasses with optimal reversible changes for creating of multilayered structure with variable width of the stop band.

\subsection{Electrostatic tuning of the photonic band gap}

The phenomena of electroabsorption due to the effect of Franz-Keldysh in crystals and glasses from $\mathrm{As}_{2} \mathrm{~S}_{3}$ were observed by (Kolomiets et al., 1970). The absorption edge is shifted to longer wavelengths due to decrease of the optical gap, $E_{\mathrm{g}}$ following the formula:

$$
\Delta E_{g}=e^{2} h^{2} S^{2} F^{2} / 24 m^{*}
$$

where $e$ and $m^{*}$ are electric charge and mass of the electron, respectively, $\mathrm{h}$ is Plank's constant, $S$ is slope of the absorption edge in the absence of the field and $F$ is the intensity of the electric field. The phenomena of the electroabsorption in chalcogenide glasses are explained through the barrier-cluster model (Banik, 2010). It assumes that an amorphous semiconductor consists of microscopic regions - perhaps closed clusters - separated from each other by potential barriers. The strong electric field increases the probability of tunnelling and optical absorption, $a$ as well. The increase of a in non-crystalline semiconductors is proportional to the squire of the intensity of the electric field $-F^{2}$ :

$$
\frac{\Delta \alpha}{\alpha}=\text { const. } F^{2}
$$

Samples from "sandwich" type were prepared for investigation of the effect of electroabsorption on the optical properties of the thin films or multilayered structure. Firstly, thin transparent electrode from chromium with $10 \mathrm{~nm}$ thickness was deposited on a glass substrate by electron beam evaporation. The transmission coefficient of the electrode in the spectral range $1200-2500 \mathrm{~nm}$ is between 70 and $80 \%$ and the electrical resistivity, $\rho=2$ $\mathrm{m} \Omega . \mathrm{cm}$. Subsiquently the investigated samples - thin layer or multilayered stack, were deposited on the chromium electrode. The structure was terminated by deposition of the second chromium electrode on the top. 
According to (Kolomiets et al., 1970) the change in the transmission, $\Delta T$, induced by electric field, depends on the photon energy $(E=h v)$. He observed that the maximal change $\Delta T$ occured at $h v=2.30 \mathrm{eV}$ applying sinusoidal electric voltage of $100 \mathrm{~V}$. In Fig. 12a the change

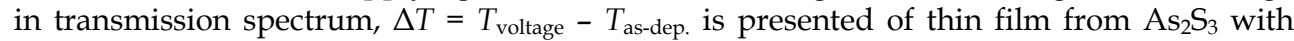
thickness $2 \mu \mathrm{m}$ due to the application of dc electric voltage $U=100 \mathrm{~V}$. The maximal value for $\Delta T$ was observed at $500 \mathrm{~nm}$, i.e. for photon energy $2.48 \mathrm{eV}$. The changes of the spectrum at longer wavelengths are smaller and are possibly "shadowed" by the interference fringes. In Fig. $12 \mathrm{~b}$ the variation is shown of the transmittance at $\lambda=500 \mathrm{~nm}$ depending on the applied electric voltage. Mathematical extrapolations showed that when the electric voltage is applied the transmittance decreases following an exponential low of the type $-T=$ $T_{0}+A_{1} \cdot \exp \left(-t / B_{1}\right)$, where $T_{0}$ is the initial value of the transmittance, $T_{0}=19.9 \% ; A_{1}=1.85$ and $B_{1}=2.58 \mathrm{~min}$ are parameters. The switching off of the electric field restores the initial value of $T$. In this case the increase can be described through the exponential low of the type $T=T_{0}+A_{2} \cdot\left[1-\exp \left(-t / B_{2}\right)\right]$ where $A_{2}=136.45$ and $B_{2}=3.63$ min are the parameters .

Considering the relationship between optical band gap and refractive index (see Penn, 1962; Wemple \& DiDomenico, 1971) it is expected the value of $n$ to increase when $E_{\mathrm{g}}$ decreases due to electroabsorption. The changes in the refractive indices of the sublayers in 1Dphotonic crystals would shift the position of their stop band. An example of the influence of the electric field on the stop band of $1 \mathrm{D}$ quaterwave structure from $\mathrm{As}_{2} \mathrm{~S}_{3} / \mathrm{PMMA}$ is presented on Fig. 13. The shift of the transmission spectrum of such a multilayer system sandwiched between two thin transparent chromium electrodes is clearly seen (Fig. 13a).
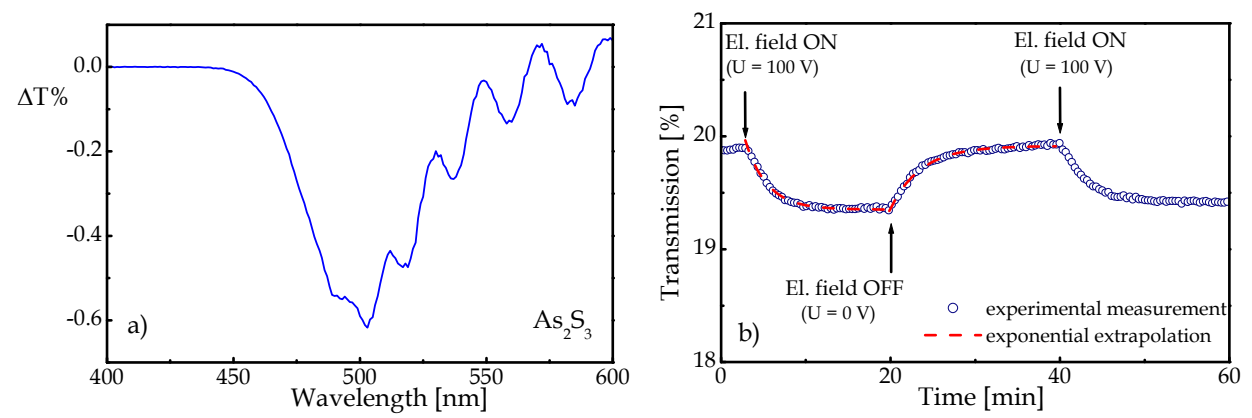

Fig. 12. Spectral dependence of the change of transmission spectrum, $\Delta T=\mathrm{T}_{\text {voltage }}-\mathrm{T}_{\text {as dep. }}$ of thin $\mathrm{As}_{2} \mathrm{~S}_{3}$ film, under dc electric voltage $100 \mathrm{~V}$ (a); Time evolution of the transmittance at $\lambda=500 \mathrm{~nm}$ depending on the applied voltage (open symbols) and extrapolations with exponential functions (dashed line) (b).

The changes in the transmission at wavelength $\lambda=1915 \mathrm{~nm}$ are given in Fig. 13b. We observed cyclic reduction or enhancing of the transmission when switch on or off the electric field. It was observed that the changes of the transmission coefficient followed the same exponential laws as the thin film from $\mathrm{As}_{2} \mathrm{~S}_{3}$ with parameters $A_{1}=3.59$ and $B_{1}=2.12 \mathrm{~min}$, when decreasing under the influence of the electric field, and $A_{2}=11120.68$ and $B_{2}=2.22$ min for the relaxation process after switching off the voltage.

The observations imply that the electric field induces reversible changes of the refractive index of the sublayers in the photonic structure. The applied electric voltage of $100 \mathrm{~V}$ is 
considerably high for applications in modern optoelectronic devices such as electrooptical modulators for high-speed time-domain-multiplexing (TDM) and wavelength-divisionmultiplexing systems (WDM). Further investigations would involve determination of the dependence of the electroabsorption effect on the composition of the chalcogenide glasses striving to reduce the voltage of the applied electric field.
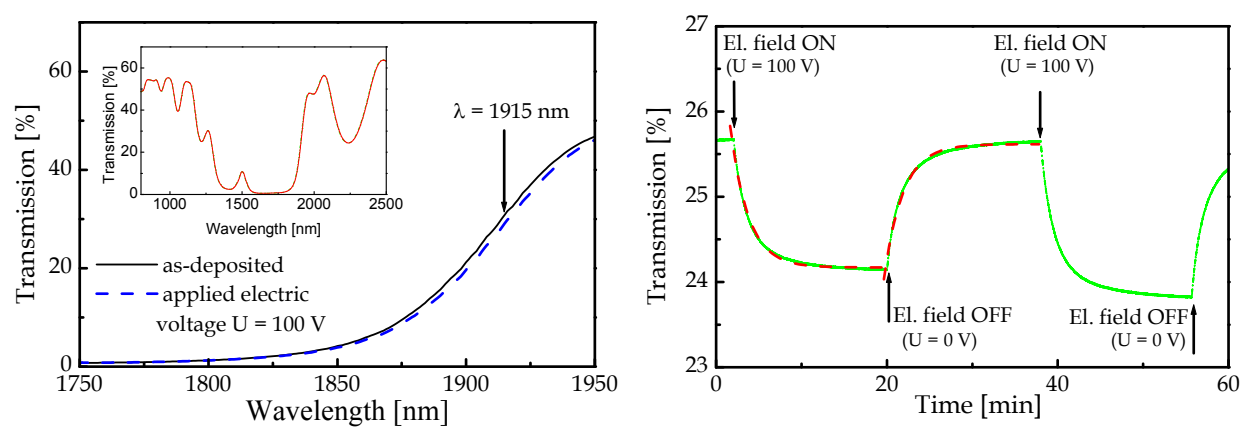

Fig. 13. Transmission spectrum of $\mathrm{As}_{2} \mathrm{~S}_{3}$ / PMMA multilayer slab between thin transparent chromium electrodes. In the inset the transmission spectrum of the same sample in wide spectral range - 800-2500 $\mathrm{nm}$ - is presented (a); Evolution of the transmission coefficient at $\lambda=500 \mathrm{~nm}$ in cyclic switching on and off of dc electric voltage $U=100 \mathrm{~V}$. The exponential extrapolations are given with a dashed line (b).

\section{Conclusion}

In this chapter we present our results on fabrication and optimization of photonic structures exploiting the photo-, thermo- and electro-induced changes in thin chalcogenide films. It is demonstrated that the irreversible and reversible changes of the optical properties of chalcogenide glasses can be used for modification of the optical contrast of materials in 1D photon photonic crystal and shift of the reflectance stop band. It was observed that the exposure to light leads to significant red shift of the resonant band (17 nm or $30 \mathrm{~nm}$ for asdeposited or annealed samples, respectively), while the annealing of the samples causes the stop band to move to shorter wavelengths - with 14 and $28 \mathrm{~nm}$ for exposed and as-deposited samples, respectively.

High electric voltage induces reversible changes of the refractive index of the sublayers in the photonic structure. It was observed a $3 \mathrm{~nm}$ red shift of the photonic stop band and decrease of the transmittance, $\Delta \mathrm{T}=2 \%$ during the applying of the dc electric voltage. Although the electric voltage of $100 \mathrm{~V}$ is considerably high for applications in optolectronics, our initial results indicate for a possible path for the implementation of reversible tuning of the stop band in $1 \mathrm{D}$ photonic crystals.

Chalcogenide glasses possess peculiar optical properties such as high linear and non-linear refractive index and transmittance in wide range of the infrared region. These unique properties make them irreplaceable materials for mid-infrared sensing, integrated optics and ultrahigh-bandwidth signal processing; recently, a new term -“chalcogenide photonics' (Eggleton et al., 2011), has been introduced. Good knowledge of the properties of the chalcogenide glasses and their changes under influence of external factors such as exposure 
to light, annealing or electric field has a key role in understanding the processes in these materials and would support manufacturing of chalcogenide photonic crystals.

\section{References}

Abdel-Aziz, M.M.; El-Metwally, E.G.; Fadel, M.; Labib, H.H. \& Afifi, M.A. (2001). Optical properties of amorphous Ge-Se-Tl system films. Thin Solid Films, Vol.386, No.1, (May 2001), pp.99-104, ISSN 0040-6090

Anne M.-L., Keirsse J., Nazabal V., Hyodo K., Inoue S., Boussard-Pledel C., Lhermite H., Charrier J., Yanakata K., Loreal O., Le Person J., Colas F., Compère C. \& Bureau B. (2009). Chalcogenide Glass Optical Waveguides for Infrared Biosensing. Sensors, Vol.9, (September 2009), pp. 7398-7411, ISSN 1424-8220

Arsh, A., Klebanov, M., Lyubin, V., Shapro, L., Feigel, A., Veigner, M. \& Sfez, B. (2004). Glassy $\mathrm{mAs}_{2} \mathrm{~S}_{3} \mathrm{nAs}_{2} \mathrm{Se}_{3}$ photoresist films for interference laser lithography. Opt. Mater. Vol.26, No.3, (August 2004), pp. 301-304, ISSN 0925-3467

Babeva, Tz.; Kitova, S. \& Konstantinov, I. (2001). Photometric methods for determining the optical constants and the thicknesses of thin absorbing films: Selection of a combination of photometric quantities on the basis of error analysis. Appl. Opt. Vol.40, No.16, (June 2001), pp.2675-2681, ISSN: 0003-6935

Babeva, Tz., Kitova S., Mednikarov, B. \& Konstantinov, I. (2002). Preparation and characterization of a reference aluminium mirror. Appl. Opt. Vol. 41, pp. 3840-3846

Banik, I. (2010). Photoconductivity In Chalcogenide Glasses In Non-Stationary Regime And The Barrier-Cluster Model. Acta Electrotechnica et Informatica, Vol. 10, No. 3, (July 2010), pp. 52-58, ISSN 1335-8243

Biegelsen, D.K. \& Street, R.A. (1980). Photoinduced defects in chalcogenide glasses, Phys. Rev. Lett. Vol.44 (12), (March 1980), pp. 803-806, ISSN: 0031-9007

Bowden, B.F. \& Harrington J.A, (2009), Fabrication and characterization of chalcogenide glass for hollow Bragg fibers. Appl. Opt. Vol.48, No. 16, (June 2009), pp.3050-3054

Barik, A.R., Adarsh, K.V., Naik, R., Ganesan, R., Yang, G., Zhao, D., Jain, H. \& Shimakawa, K. (2011). Role of rigidity and temperature in the kinetics of photodarkening in $\mathrm{Ge}_{x} \mathrm{As}_{(45-\mathrm{x})} \mathrm{Se}_{55}$ thin films. Opt. Express, Vol.19, No.14, (July 2011), pp. 13158-13163, ISSN: 1094-4087

Beev, K., Sainov, S., Stoycheva-Topalova R. (2007). Total internal reflection holographic recording in chalcogenide glass films. J. Optoelectron. Adv. M., Vol.9, No.2, (February 2007), pp. 341-343, ISSN 1454-4164

Blanco, A., Chomski, E., Grabtchak, S., Ibisate, M., John, S., Leonard, S.W., Lopez, C., Meseguer, F., Miguez, H., Mondla, J.P., Ozin, G.A., Toader, O., Van Driel, H.M. (2000). Large-scale synthesis of a silicon photonic crystal with a complete threedimensional bandgap near 1.5 micrometres. Nature, Vol. 405, No. 6785, (May 2000), pp.437-440 ISSN: 0028-0836

Blanco, A., Busch, K., Deubel, M., Enkrich Ch., Von Freyman, G., Hermatschweiler, M., Koch, W-P., Linden, S., Meisel, D.C., Wegener, M. (2004) Three-dimensional lithography of photonic crystals, In: Photonic crystals - advances in design, fabrication and characterization", K. Busch, S. Lolkes, R.B. Wehrspohn, and H. Foll, (Ed.'s), Wiley - VCH, Weinheim, 153-173, Darmstadt, Germany

Boyd, R.W. (2003). Nonlinear Optics, second edition, Academic Press, Elsevier Science, USA

Braun, P.V., Rinne, S.A. \& Garcia-Santamaria, F. (2006). Introducing defects in 3D photonic crystals: State of the art. Adv. Mat. Vol.18, No. 20, pp.2665-2678, ISSN: 09359648 
Bureau, B., Zhang, X.H., Smektala, F., Adam, J.-L., Lucas, J., Troles, J., Ma, H.-L., BoussardPledel, C., Lucas, P., Le Coq, D., Riley, M.R. \& Simmons, J.H. (2004). Recent advances in chalcogenide glasses. J. Non-Cryst. Solids, Vol.345\&346, (October 2004), pp. 276-283, ISSN 0022-3093

Cai, L.Z., Yang, X.L. \& Y.R. Wang, Y.R. (2002). All fourteen Bravais lattices can be formed by interference of four noncoplanar beams. Opt. Lett. Vol. 27, No.11, (June 2002), pp.900-902, ISSN: 0146-9592

Cardinal, T., Richardson, K.A., Shim, H., Shulte, A., Beatty, R., Le Foulgoc, K., Viens, J. F., Villeneuve, A. (1999). Non-linear optical properties of chalcogenide glasses in the system As-S-Se. J. Non-Cryst. Solids, Vol.256\&257, pp.353-360, ISSN 0022-3093

Charpentier, F., Bureau., B., Troles, J., Boussard-Plédel, C., Michel-Le Pierrès, K., Smektala, F., Adam, J.-L. (2009). Infrared monitoring of underground $\mathrm{CO}_{2}$ storage using chalcogenide glass fibers. Opt. Mater. Vol.31, No.3, pp.496-500, ISSN 0925-3467

Conseil, C., Coulombier, Q., Boussard-Plédel, C., Troles, J., Brilland, L., Renversez, G., Mechin, D., Bureau, B., Adam, J.L. \& Lucas, J. (2011). Chalcogenide step index and microstructured single mode fibers. J. Non-Cryst. Solids, Vol.357, No.11-13, (June 2011), pp. 2480-2483, ISSN 0022-3093

DeCorby, R.G., Nguyen, H.T., Dwivedi, P.K. \& Clement, T.J. (2005). Planar omnidirectional reflectors in chalcogenide glass and polymer. Opt. Express Vol.13, No.16 pp.62286233, ISSN: 1094-4087

De Neufville, J.P., Moss, S.C. \& Ovshinsky, S.R. (1974), Photostructural transformations in amorphous $\mathrm{As}_{2} \mathrm{Se}_{3}$ and $\mathrm{As}_{2} \mathrm{~S}_{3}$ films, J. Non-Cryst. Solids, Vol.13, No.2, (January 1974), pp. 191-223, ISSN: 0022-3093

Divlianski, I., Mayer, T.S., Holliday, K.S. \& Crespi, V.H. (2003). Fabrication of threedimensional polymer photonic crystal structures using single diffraction element interference lithography. Appl. Phys. Lett. Vol.82, No.11, (March 2003), pp.16671169, ISSN: 0003-6951

Eggleton, B.J., Luther-Davies, B. \& Richardson, K. (2011). Chalcogenide photonics. Nature Photonics, Vol.5, No.3, (March 2011), pp.141-148, ISSN: 17494885

Egen, M., Zentel, R., Ferrand, P., Eiden, S, Maret, G., \& Caruso, F. (2004), Preparation of 3D photonic crystal from opals, In: Photonic crystals - advances in design, fabrication and characterization, K. Busch, S. Lolkes, R.B. Wehrspohn, \& H. Foll, (Ed.'s), 109-128, Wiley - VCH, Weinheim, ISBN: 978-3-527-40432-2, Darmstadt, Germany

Eisenberg, N.P., Manevich, M., Arsh, A., Klebanov, M. \& Lyubin, V., (2005), Arrays of micro-prisms and micro-mirrors for infrared light based on $\mathrm{As}_{2} \mathrm{~S}_{3}-\mathrm{As}_{2} \mathrm{Se}_{3}$ photoresists., J. Optoelectron. Adv. M. Vol.7, No.5, pp. 2275-2280, ISSN 1454-4164

Feigel, A., Veinger, M., Sfez, B., Arsh, A., Klebanov, M., \& Lyubin, V. (2005). Two dimensional photonic band gap pattering in thin chalcogenide glassy films, Thin Solid Films Vol.488, No.1-2, (September 2005), pp.185-188, ISSN: 0040-6090

Feigel, A., Veinger, M., Sfez, B., Arsh, A., Klebanov, M. \& Lyubin, V. (2003). Threedimensional simple cubic woodpile photonic crystals made from chalcogenide glasses. Appl. Phys. Lett. Vol.83, No.22, (Dec. 2003), pp.4480-4482, ISSN: 0003-6951

Fink, Y., Winn, J.N., Fan, S., Chen, C., Michel, J, Joannopoulos, J.D. \& Thomas, E.L. (1998). A dielectric omnidirectional reflector, Science, Vol.282, No. 20, (November 1998), pp. 1679-1682, ISSN: 00368075

Fischer, W. (2001). A Second Note on the Term "Chalcogen". J. Chem. Educ. Vol.7, No.10, pp. 1333, ISSN 0021-9584 
Freeman, D., Madden, S. \& Luther-Davies, B. (2005). Fabrication of planar photonic crystals in a chalcogenide glass using a focused ion beam. Opt. Express, Vol.13, No.8, pp.3079-3086, ISSN 1094-4087

Fritzsche. H. (1998). Toward understanding the photoinduced changes in chalcogenide glasses. Semiconductors, Vol.32, No.8, (August 1998), pp. 850-854, ISSN 1063-7826

Ganjoo, A., Jain, H., Yu, C., Song, R., Ryan, J.V., Irudayaraj, J., Ding, Y.J. \& Pantano, C.G. (2006). Planar chalcogenide glass waveguides for IR evanescent wave sensors. J. Non-Cryst. Solids, Vol.352, (May 2006), pp. 584-588, ISSN 0022-3093

Ho, K., Chan, C. \& Soukoulis, C. (1990). Existence of a photonic gap in periodic dielectric structures. Phys. Rew. Lett. Vol.65, No.23, pp. 3152-3155, ISSN 1079-7114

Houizot, P., Boussard-Plédel, C., Faber, A. J., Cheng, L. K., Bureau, B., Van Nijnatten, P. A., Gielesen, W. L. M., Pereira do Carmo, J., Lucas, J. (2007). Infrared single mode chalcogenide glass fiber for space. Opt. Express Vol.15, (Sep. 2007), pp. 12529-12538.

Joanopoulus, J.D., Meade, R.D. \& Winn, J.N. (1995). Photonic crystals: Molding the Flow of Light, Princeton University Press, ISBN: 9781400828241, Princeton, USA

John, S. (1987). Strong localization of photons in certain disordered dielectric superlattices, Phys. Rew. Lett. Vol.58, No.23, pp. 2486-2489, ISSN 1079-7114

Kastner, M., Adler, D., Fritzsche, H. (1976), Valence-Alternation Model for Localized Gap States in Lone-Pair Semiconductors. Phys. Rev. Lett. Vol.37, No.22, pp. 1504-1507, ISSN 0031-9007

Kawata, S., Sun, H.B., Tanaka, T., \& Tanaka, K. (2001). Finer features for functional microdevices, Nature, 412, No. 6848, (August 2001), pp. 697-698, ISSN: 0028-0836

Kim, S.H \& C K. Hwangbo, C.K. (2002). Design of omnidirectional high reflectors with quarter-wave dielectric stacks for optical telecommunication bands. Appl. Opt. Vol. 41, No. 16, (June 2002), pp. 3187-3192, ISSN: 0003-6935

Kincl, M., Tasseva, J., Petkov, K., Knotek, P., Tichy, L., (2009) On the photo-induced shift of the optical gap in amorphous $\mathrm{Ge}_{6} \mathrm{As}_{43} \mathrm{~S}_{35} \mathrm{Se}_{16}$ film., J. Optoelectron. Adv. M., Vol.11 No.4, (April 2009), pp. 395-398, ISSN 1454-4164

Kohoutek, T., Wagner, T., Orava, J., Krbal, M., Ilavsky, J., Vesely, D. \& Frumar, M. (2007a). Multilayer systems of alternating chalcogenide As-Se and polymer thin films prepared using thermal evaporation and spin-coating techniques. J. Phys. Chem. Solids, Vol.68, No.5, (May 2007), pp. 1268-1271, ISSN: 0022-3697

Kohoutek, T., Orava, J., Hrdlicka, M., Wagner, T., Vlcek, Mil., Frumar, M, (2007b). Planar quarter wave stacks prepared from chalcogenide Ge-Se and polymer polystyrene thin films. J. Phys. Chem. Solids Vol.68 No.12, (December 2007), pp. 2376-2380

Kohoutek, T., Orava, J., Prikryl, J., Wagner, T., Vlcek, Mil., Knotek, P. \& Frumar, M. (2009b). Planar chalcogenide quarter wave stack filter for near-infrared. J. Non-Cryst. Solids, Vol.355, No.28-30, (August 2009), pp.1521-1525, ISSN: 0022-3093

Kolomiets, B.T., Mazets, T.F. \& Efendief, Sh.M. (1970), On The Energy Spectrum Of Vitreous Arsenic Sulphide, J. Non-Cryst. Solids, Vol.4, (April 1970), pp.45-56, ISSN: 0022-3093

Konstantinov, I.; Babeva, Tz.; \& Kitova, S. (1998), Analysis of errors in thin-film optical parameters derived from spectrophotometric measurements at normal light incidence, Appl. Opt. Vol.37, No.19, pp.4260 -4267, ISSN: 0003-6935

Kovalskiy, A., Vlček, M., Jain, H., Fiserova, A., Waits, C.M. \& Dubey, M. (2006). Development of chalcogenide glass photoresists for gray scale lithography. J. NonCryst. Solids, Vol.352, No.6-7, (May 2006), pp. 589 - 594, ISSN 0022-3093

Knotek, P., Tasseva, J., Petkov, K., Kincl, M. \& Tichy, L. (2009). Optical properties and scanning probe microscopy study of some Ag-As-S-Se amorphous films. Thin Solid Films, Vol.517, No.20, (August 2009), pp. 5943-5947, ISSN 0040-6090 
Lai, N.D., Liang, W.P., Lin, J.H., Hsu, C.C. \& Lin, C.H. (2005). Fabrication of two- and threedimensional periodic structures by multi-exposure of two beam interference technique. Opt. Express, Vol.13, No.23, (Nov. 2005), pp. 9605-9611, ISSN: 094-4087

Lee, M.W.; Grillet, Ch; Smith, C.L.C.; Moss, D.J., Eggleton, B.J.; Freeman, D.; Luther-Davies, B., Madden, S., Rode, A.; Ruan, Y. \& Lee, Y-h. (2007). Photosensitive post tuning of chalcogenide photonic crystal waveguides, Opt. Express Vol. 15, No. 3, pp. 12771285, ISSN: 094-4087

Li, W., Seal, S., Rivero, C., Lopez, C., Richardson, K., Pope, A., Schulte, A., Myneni, S., Jain, H., Antoine, K. \& Miller, A.C. (2002). X-ray photoelectron spectroscopic investigation of surface chemistry of ternary As-S-Se chalcogenide glasses. J. Appl. Phys. Vol.92, No.12, (December 2002), pp. 7102-7108, ISSN: 00218979

Liao, M., Chaudhari, C., Qin, G., Yan, X., Kito, C., Suzuki, T., Ohishi, Y., Matsumoto, M. \& Misumi, T. (2009). Fabrication and characterization of a chalcogenide-tellurite composite microstructure fiber with high nonlinearity. Opt. Express, Vol.17, No.24, (November 2009), pp. 21608-21614, ISSN 1094-4087

Liu, Q., Zhao, X., Gan, F., Mi, J., Qian, S. (2005). Ultrafast optical kerr effect in amorphous $\mathrm{Ge}_{10} \mathrm{As}_{40} \mathrm{~S}_{30} \mathrm{Se}_{20}$ films induced by ultrashort laser pulses. J. Optoelectron. Adv. M., Vol.7, No.3, (March 2007), pp. 1323-1328, ISSN 1454-4164

Lopez, C. (2003). Materials Aspects of Photonic Crystals. Adv. Mater. Vol.15, No.20, (October 2003), pp. 1679-1704, ISSN: 09359648

Lyubin, V. (1984). Photographic processes on the base of the chalcogenide glassy semiconductors, In: Non-silver photographic processes, A. Kartuzhanskovo (Ed.), pp. 188-208, Khimiyia, Leningrad (St. Petersburg), Russia (in Russian)

Marquez, E., Gonzalez-Leal, J.M., Bernal-Oliva, A.M., Wágner, T., \& Jimenez-Garay, R. (2007), Preparation and optical dispersion and absorption of Ag-photodoped $\mathrm{Ge}_{x} \mathrm{Sb}_{40-\mathrm{x}} \mathrm{S}_{60}(\mathrm{x} \leq 10,20$ and 30) chalcogenide glass thin films, J. Phys. D: Appl. Phys. Vol.40, No.17, (September 2007), pp. 5351-5357, ISSN: 0022-3727

Milam, D. (1998) Review and Assessment of Measured Values of the Nonlinear RefractiveIndex Coefficient of Fused Silica. Appl. Opt. Vol.37, No.3, (January 1998), pp. 546550, ISSN 1559-128X

Mizrahi, V., DeLong, K.W., Stegeman, G.I., Saifi, M. A., Andrejco, M. J., (1989), Two-photon absorption as a limitation to all-optical switching. Opt. Lett. Vol.14, No.20, pp.11401142, ISSN 0146-9592

Nicoletti, E., Zhou, G., Jia, B., Ventura, M.J., Bulla, D., Luther-Davies, B. \& Gu, M. (2008). Observation of multiple higher-order stopgaps from three-dimensional chalcogenide glass photonic crystals. Opt. Lett. Vol.33, No.20, (October 2008), pp.2311-2313, ISSN: 0146-9592

Okuda, M., Tri Nang, T. \& Matsushita, T. (1979). Photo-induced absorption changes in selenium-based chalcogenide glass films. Thin Solid Films, Vol.58, No.2, (April 1979), pp. 403-406, ISSN 0040-6090

Ogusu, K., Maeda, S., Kitao, M., Li, H. \& Minakata, M. (2004). Optical and structural properties of $\mathrm{Ag}(\mathrm{Cu})-\mathrm{As}_{2} \mathrm{Se}_{3}$ chalcogenide films prepared by a photodoping. $J$. Non-Cryst. Solids Vol.347, No.1-3, (November 2004), pp. 159-165, ISSN: 00223093

Penn, D.R. (1962). Wave-Number-Dependent Dielectric Function of Semiconductors, Phys. Rev. Vol.128, pp. 2093-2097, ISSN: 0031-899X

Petkov, K., Todorov, R., Tasseva, J. \& Tsankov, D. (2009). Structure, linear and non-linear optical properties of thin $\mathrm{As}_{\mathrm{x}} \mathrm{Se}_{1-\mathrm{x}}$ films. J. Optoelectron. Adv. M., Vol.11, No.12, (December 2009), pp.2083-2091, ISSN 1454-4164 
Ponnampalam, N. \& DeCorby R. (2008). Analysis and fabrication of hybrid metal-dielectric omnidirectional Bragg reflectors. Appl. Opt. Vol. 47, pp. 30-37, ISSN 1464-4258

Raptis, C., Kotsalas, I.P., Papadimitriou, D., Vlcek, M., Frumar, M. (1997). Physics and Applications of Non-crystalline Semiconductors in Optoelectronics, NATO ASI Series, 3. High Technology, 36, p. 291, M. Bertolotti, A. Andriesh (Eds.)

Riley, B.J., Sundaram, S.K., Johnson, B.R., Saraf, L.V. (2008). Differential etching of chalcogenides for infrared photonic waveguide structures. J. Non-Cryst. Solids, Vol.354, No.10-11, (February 2008), pp. 813-816, ISSN 0022-3093

Rowlands, C.J., Su, L. \& Elliott, S.R. (2010). Rapid prototyping of low-loss IR chalcogenideglass waveguides by controlled remelting. Chem.Phys.Chem., Vol.11, No.11, (August 2010), pp. 2393-2398, ISSN 1439-4235

Saithoh A., Gotoh, T. \& Tanaka, K. (2002). Chalcogenide-glass microlenses for optical fibers. J Non-Cryst. Solids, Vol.299-302, (April 2002), pp. 983-987, ISSN 0022-3093

Sakoda K. (2005) Optical Properties of Photonic Crystals, W. T. Rhodes (Ed), SpringerVerlag Berlin, Heidelberg, Germany, ISSN 0342-4111

Savović, S. \& Djordjevich, A. (2011). Mode coupling in chalcogenide-glass optical fibers. Opt. Laser. Eng. Vol.49, No.7, (July 2011), pp. 855-858, ISSN 0143-8166

Sheik-Bahae, M., Hagan, D. J., Van Stryland, E. W. (1990). Dispersion and band-gap scaling of the electronic Kerr effect in solids associated with two-photon absorption. Phys. Rev. Lett., Vol.65, No.1, pp. 96-99, ISSN 0031-9007

Shimakawa, K., Kolobov, A. \& Elliott, S.R. (1995). Photoinduced effects and metastability in amorphous semiconductors and insulators, Adv. Phys. Vol.44, No.6, (November 1995), pp.475-588, ISSN: 00018732

Skordeva, E., Arsova, D., Aneva, Z., Vuchkov, N., Astadjov, D. (2001). Laser induced photodarkening and photobleaching in Ge-As-S thin films. Proceedings of SPIE - The International Society for Optical Engineering, Vol.4397, pp. 348-352, ISSN 0277786X

Street, R.A. (1977). Non-radiative recombination in chalcogenide glasses. Solid State Communications, Vol.24, No.5, (November 1979), pp. 363-365, ISSN: 00381098

$\mathrm{Su}$, L., Rowlands, C.J., Lee, T.H., Elliott, S.R. (2008). Fabrication of photonic waveguides in sulfide chalcogenide glasses by selective wet-etching, Electron. Lett., Vol.44, No.7, pp. 472-474, ISSN 0013-5194

Su, L., Rowlands, C.J. \& Elliott, S.R. (2009). Nanostructures fabricated in chalcogenide glass for use as surface-enhanced Raman scattering substrates. Opt. Lett. Vol.34, No.11, (June 2009), pp.1645-1647, ISSN: 0146-9592

Swanepoel, R. (1983). Determination of the thickness and optical constants of amorphous silicon, J.Phys. E: Sci. Instrum. Vol.16, No.12, pp.1214-1222, ISSN: 0022-3735

Tanaka, K. \& Ohtsuka, Y. (1979). Composition dependence of photo-induced refractive index changes in amorphous As-S films, Thin Solid Films, Vol.57 No. 1, (February 1979), pp. 59-64, ISSN 0040-6090

Tanaka, K. (2007). Nonlinear optics in glasses: How can we analyze? J. Phys. Chem. Solids, Vol.68, No.5-6, (May 2007), pp. 896-900, ISSN 0022-3697

Tasseva, J., Petkov, K., Kozhuharova, D. \& Iliev, Tz. (2005). Light-induced changes in the physico-chemical and optical properties of thin Ge-S- Se-As films. J. Optoelectron. Adv. M., Vol.7, No.3, (March 2005), pp. 1287-1292, ISSN 1454-4164

Tasseva, J., Lozanova, V., Todorov, R., Petkov, K. (2007). Optical Characterization of Ag/ AsS-Se thin films. J. Optoelectron. Adv. M., Vol.9, No.10, pp. 3119-3124, ISSN 1454-4164 
Tasseva, J., Todorov, R., Babeva, Tz. \& Petkov, K. (2010). Structural and optical characterization of $\mathrm{Ag}$ photo-doped thin $\mathrm{As}_{40} \mathrm{~S}_{60-\mathrm{x}} \mathrm{Se}_{\mathrm{x}}$ films for nonlinear applications., J. Opt., Vol.12, (June 2010), pp. 065601 (9 pp), ISSN 1464-4258

Teteris, J., Reinfelde, M. (2004). Subwavelength-period gratings in amorphous chalcogenide thin films. J. Opt. A: Pure Appl. Opt. Vol.6, No.3, pp. S151 -S154, ISSN 1464-4258

Tichy, L., Ticha, H., Blecha, J. \& Vlcek, M. (1993). Compositional trend of the blue shift of the gap in $\mathrm{Ge}_{x} \mathrm{~S}_{100-x}$ thin amorphous films induced by annealing and illumination. Mater. Lett. Vol.17, No.5, pp. 268-273

Tikhomirov, V.K., Furniss, D., Seddon, A.B., Savage, J.A., Mason, P.D., Orchard D.A. \& Lewis K.L. (2004). Glass formation in the Te-enriched part of the quaternary Ge-AsSe-Te system and its implication for mid-infrared optical fibres. Infrared Phys. Technol. Vol.45, No.2, (March 2004), pp. 115-123, ISSN: 13504495

Todorov, R. \& Petkov, K, (2001). Light induced changes in the optical properties of thin As $\mathrm{S}-\mathrm{Ge}(\mathrm{Bi}, \mathrm{Tl})$ films. J. Optoelectron. Adv. M., Vol.3, No.2, pp. 311-317, ISSN 1454-4164

Todorov, R., Iliev, Tz., Petkov, K. (2003). Light-induced changes in the optical properties of thin films of Ge-S-Bi(Tl, In) chalcogenides. J. Non-Cryst. Solids, Vol. 326-327, (October 2003), pp. 263-267, ISSN 0022-3093

Todorov, R., Paneva, A., \& Petkov K. (2010a). Optical characterization of thin chalcogenide films by multiple-angle-of-incidence ellipsometry, Thin Solid Films, Vol.518, No.12, (April 2010), pp.3280-3288, ISSN: 00406090

Todorov, R., Tasseva, J., Babeva, Tz. \& Petkov K. (2010b). Multilayered $\mathrm{As}_{2} \mathrm{Se}_{3} / \mathrm{GeS}_{2}$ quarterwave structures for photonic applications, J. Phys. D: Appl. Phys. Vol.43 No.50, (December 2010) art. num. 505103 (8pp), ISSN: 0022-3727

Ung, B. \& Skorobogatiy, M. (2011). Extreme nonlinear optical enhancement in chalcogenide glass fibers with deep-subwavelength metallic nanowires. Opt. Lett. Vol.36, No.12, (June 2011), pp. 2527-2529, ISSN 0146-9592

Vlaeva, I., Petkov, K., Tasseva, J., Todorov, R., Yovcheva, T. \& Sainov, S. (2010). Electric charging influence on the diffraction efficiency of total internal reflection holograms, recorded in very thin chalcogenide films, J. Opt., Vol.12, No.12, (December 2010), pp. 124008 (6pp), ISSN 1464-4258

Wágner, T. \& Ewen, P.J.S., (2000), Photo-induced dissolution effect in Ag/ $\mathrm{As}_{33} \mathrm{~S}_{67}$ multilayer structures and its potential application. J. Non-Cryst. Solids, Vol.266-269, (May 2000), pp. 979-984, ISSN 0022-3093

Wemple S. \& DiDomenico, Jr., M. (1971). Behavior of the Electronic Dielectric Constants in Covalent and Ionic Materials, Physical Review B, Vol.3, No.14, (February 1971), pp.1338-1351, ISSN: 0163-1829

Yablonovitch, E. (1987). Inhibited Spontaneous Emission in Solid-State Physics and Electronics, Phys. Rew. Lett. Vol.58, No. 20, pp.2059-2062, ISSN 1079-7114

Yablonovitch, E., Gmitter, T.J. \& Leung, K. M. (1991). Photonic band gap structure: The facecentered-cubic case employing nonspherical atoms. Phys. Rev. Lett. Vol. 67, No.17, (October 1991), pp. 2295-2301, ISSN: 0031-9007

Yablonovitch, E. (2007). Photonic crystals: What's in a name? Optics and Photonics News, Vol.18, No.3, pp.12-13, ISSN: 10476938

Zakery A. \& Elliott, S.R. (2007). Optical Nonlinearities in Chalcogenide Glasses and their Applications, Springer Series in optical sciences, ISBN-10 3-540-71066-3, Springer Berlin, Heidelberg, New York

http://glassonline.com/infoserv/history.html 


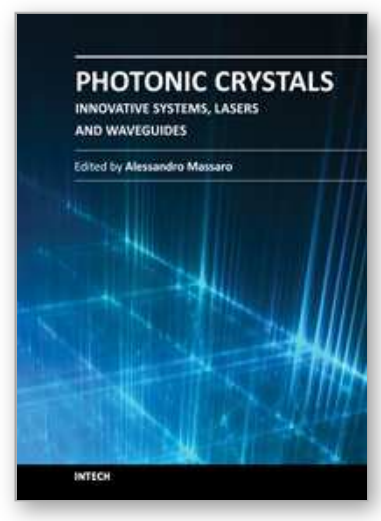

\author{
Photonic Crystals - Innovative Systems, Lasers and Waveguides \\ Edited by Dr. Alessandro Massaro
}

ISBN 978-953-51-0416-2

Hard cover, 348 pages

Publisher InTech

Published online 30, March, 2012

Published in print edition March, 2012

The second volume of the book concerns the characterization approach of photonic crystals, photonic crystal lasers, photonic crystal waveguides and plasmonics including the introduction of innovative systems and materials. Photonic crystal materials promises to enable all-optical computer circuits and could also be used to make ultra low-power light sources. Researchers have studied lasers from microscopic cavities in photonic crystals that act as reflectors to intensify the collisions between photons and atoms that lead to lazing, but these lasers have been optically-pumped, meaning they are driven by other lasers. Moreover, the physical principles behind the phenomenon of slow light in photonic crystal waveguides, as well as their practical limitations, are discussed. This includes the nature of slow light propagation, its bandwidth limitation, coupling of modes and particular kind terminating photonic crystals with metal surfaces allowing to propagate in surface plasmon-polariton waves. The goal of the second volume is to provide an overview about the listed issues.

\title{
How to reference
}

In order to correctly reference this scholarly work, feel free to copy and paste the following:

Rossen Todorov, Jordanka Tasseva and Tsvetanka Babeva (2012). Thin Chalcogenide Films for Photonic Applications, Photonic Crystals - Innovative Systems, Lasers and Waveguides, Dr. Alessandro Massaro (Ed.), ISBN: 978-953-51-0416-2, InTech, Available from: http://www.intechopen.com/books/photonic-crystalsinnovative-systems-lasers-and-waveguides/thin-chalcogenide-films-for-photonic-applications

\section{INTECH}

open science | open minds

\section{InTech Europe}

University Campus STeP Ri

Slavka Krautzeka 83/A

51000 Rijeka, Croatia

Phone: +385 (51) 770447

Fax: +385 (51) 686166

www.intechopen.com

\section{InTech China}

Unit 405, Office Block, Hotel Equatorial Shanghai

No.65, Yan An Road (West), Shanghai, 200040, China

中国上海市延安西路65号上海国际贵都大饭店办公楼 405 单元

Phone: +86-21-62489820

Fax: $+86-21-62489821$ 
(C) 2012 The Author(s). Licensee IntechOpen. This is an open access article distributed under the terms of the Creative Commons Attribution 3.0 License, which permits unrestricted use, distribution, and reproduction in any medium, provided the original work is properly cited. 